\title{
Early pridopidine treatment improves behavioral and transcriptional deficits in YAC128 Huntington disease mice
}

\author{
Marta Garcia-Miralles, ${ }^{1}$ Michal Geva, ${ }^{2}$ Jing Ying Tan, ${ }^{1}$ Nur Amirah Binte Mohammad Yusof, ${ }^{1}$ \\ Yoonjeong Cha, ${ }^{3}$ Rebecca Kusko, ${ }^{3}$ Liang Juin Tan, ${ }^{1}$ Xiaohong Xu, ${ }^{1}$ Iris Grossman, ${ }^{2}$ Aric Orbach, ${ }^{2}$ \\ Michael R. Hayden, ${ }^{1,2,4,5}$ and Mahmoud A. Pouladi ${ }^{1,5}$ \\ 'Translational Laboratory in Genetic Medicine, Agency for Science, Technology and Research, Singapore (A*STAR), \\ Singapore. ${ }^{2}$ Teva Pharmaceutical Industries Ltd., Petach Tikva, Israel. ${ }^{3}$ Immuneering Corporation, Cambridge, \\ Massachusetts, USA. ${ }^{4}$ Centre for Molecular Medicine and Therapeutics, Child and Family Research Institute, University \\ of British Columbia, Vancouver, British Columbia, Canada. ${ }^{5}$ Department of Medicine, Yong Loo Lin School of Medicine, \\ National University of Singapore, Singapore.
}

\begin{abstract}
Pridopidine is currently under clinical development for Huntington disease (HD), with on-going studies to better characterize its therapeutic benefit and mode of action. Pridopidine was administered either prior to the appearance of disease phenotypes or in advanced stages of disease in the YAC128 mouse model of HD. In the early treatment cohort, animals received 0,10, or $30 \mathrm{mg} /$ $\mathrm{kg}$ pridopidine for a period of $\mathbf{1 0 . 5}$ months. In the late treatment cohort, animals were treated for 8 weeks with $0 \mathrm{mg} / \mathrm{kg}$ or an escalating dose of pridopidine ( 10 to $30 \mathrm{mg} / \mathrm{kg}$ over 3 weeks). Early treatment improved motor coordination and reduced anxiety- and depressive-like phenotypes in YAC128 mice, but it did not rescue striatal and corpus callosum atrophy. Late treatment, conversely, only improved depressive-like symptoms. RNA-seq analysis revealed that early pridopidine treatment reversed striatal transcriptional deficits, upregulating disease-specific genes that are known to be downregulated during HD, a finding that is experimentally confirmed herein. This suggests that pridopidine exerts beneficial effects at the transcriptional level. Taken together, our findings support continued clinical development of pridopidine for HD, particularly in the early stages of disease, and provide valuable insight into the potential therapeutic mode of action of pridopidine.
\end{abstract}

Conflict of interest: Teva Pharmaceutical Industries Ltd. played no role in the treatment or testing of animals or the collection, analysis, and interpretation of the results.

Submitted: July 5, 2017 Accepted: November 1, 2017 Published: December 7, 2017

\section{Reference information:} JCI Insight. 2017;2(23):e95665. https://doi.org/10.1172/jci. insight. 95665.

\section{Introduction}

Huntington disease (HD) is a progressive, neurodegenerative disorder caused by a dominant mutation in the HTT gene; it is characterized by motor, cognitive, and neuropsychiatric disturbances. Mutant HTT (mHTT) has been shown to disrupt a number of cellular and molecular processes that are thought to contribute collectively to clinical manifestations of the disease. These include transcriptional dysfunction $(1,2)$, deficits in trophic support (2-4), and imbalances in neurotransmitter levels and signaling $(5,6)$ as well as aberrant calcium handling by synaptic $(7,8)$, ER $(7,8)$, and mitochondrial pathways (9).

Pridopidine, a phenylpiperidine, is currently under clinical development for HD. Although initially thought to act predominantly via the $\mathrm{D} 2$ dopamine receptor (D2R), recent evidence shows that pridopidine has a higher affinity for the sigma-1 receptor (S1R) (10) and that its pharmacodynamic properties are more consistent with S1R activation (10). S1R is a transmembrane protein that normally resides in the mitochondria-associated membrane domains of the ER $(9,11)$. S1R activation has been associated with neuroprotection and improved neuroplasticity at least partly through improved calcium homeostasis (12). S1R-activating ligands have also been shown to modulate cholinergic neurotransmission (13) and to have antiamnesic properties in models of Alzheimer's disease (AD) and cognitive decline (13). Conversely, mutations in S1R have been causally linked with a number of neurodegenerative disorders, including juvenile amyotrophic lateral sclerosis (14), frontotemporal lobar degeneration-motor neuron disease (15), and hereditary motor neuropathy (16). Furthermore, genetic polymorphisms in $\mathrm{S} 1 \mathrm{R}$ have been described as genetic risk factors for $\mathrm{AD}$, influencing the severity of the disorder (17). 
A

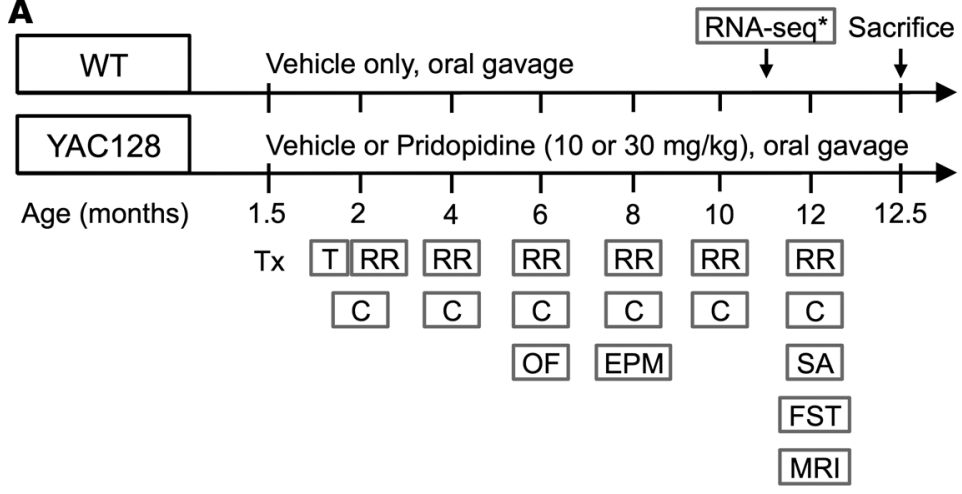

B

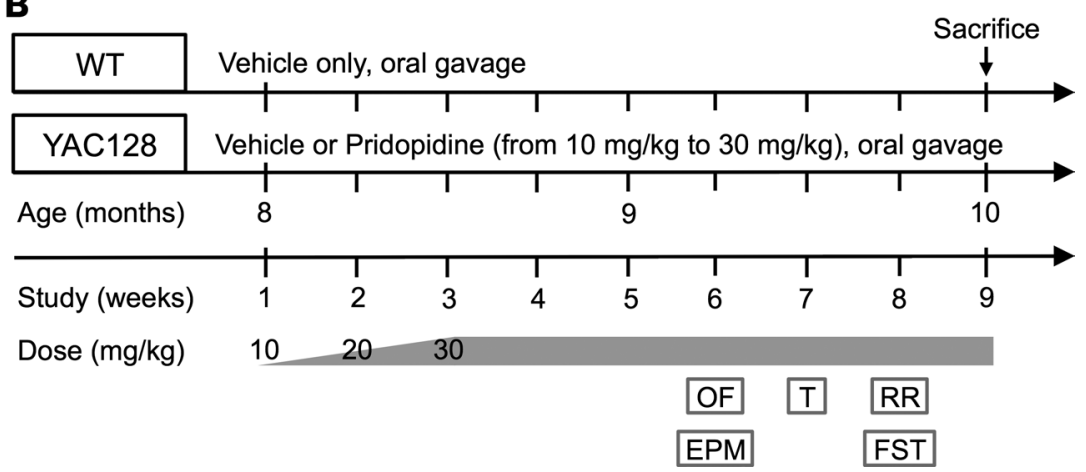

Figure 1. Schematic representation of the experimental design for the early and late pridopidine study in YAC128 HD mice. (A) Early pridopidine treatment study design. WT mice were administered vehicle $\left(\mathrm{ddH}_{2} \mathrm{O}\right)$ only, whereas YAC128 HD mice were administered either vehicle $\left(\mathrm{ddH}_{2} \mathrm{O}\right)$ or pridopidine $(10$ or $30 \mathrm{mg} / \mathrm{kg}$ ). Treatment started at 1.5 months of age (premanifest) and continued for 10.5 months. (B) Late pridopidine treatment study design. WT mice were administered vehicle $\left(\mathrm{ddH}_{2} \mathrm{O}\right)$ only, whereas YAC128 HD mice were administered either vehicle $\left(\mathrm{ddH}_{2} \mathrm{O}\right)$ or an escalating dose of pridopidine $(10 \mathrm{mg} / \mathrm{kg}$ in week $1,20 \mathrm{mg} / \mathrm{kg}$ in week 2 , and $30 \mathrm{mg} / \mathrm{kg}$ in weeks 3-8). Treatment started at 8 months of age (manifest) and continued for 2 months. For both $\mathbf{A}$ and $\mathbf{B}$, a set of behavioral tests were carried out as indicated. For B, MRI was also performed. *RNA-seq was performed on an independent cohort of mice. Tx, treatment initiation; T, motor learning; RR, accelerating rotarod; C, climbing test; OF, open field; EPM, elevated plus maze; SA, spontaneous activity test; FST, forced swim test.

Alterations in S1R expression levels have been described in different models of HD, suggesting a potential link between S1R and disease pathology $(8,18)$. Treatment with the S1R agonist, PRE084, has been shown to reverse S1R expression levels in PC6.3 neuronal cells and protect against mHTT-induced neurodegeneration (18). Similarly, pridopidine treatment improved motor function and induced neuroprotective effects in the R6/2 mouse model of $\mathrm{HD}$ (19). While it is possible that pridopidine acts through multiple pathways, a recent publication, using corticostriatal cocultures from YAC128 HD mice in which S1R was deleted, demonstrates that pridopidine's synaptoprotective activity is S1R dependent (8).

While recent studies have provided insights into the therapeutic benefits and potential mechanism of action of pridopidine, the differential effects of pridopidine across stages of disease remain largely unknown. Such information, together with a better understanding of pridopidine's mode of action, is valuable in informing further clinical evaluation of its efficacy. Here, we sought to evaluate the therapeutic potential of pridopidine in the YAC128 mouse model of HD. For this purpose, pridopidine was administered prior to (early treatment) the onset of disease-related phenotypes and in advanced disease stages (late treatment) in YAC128 HD mice, and its efficacy was comprehensively assessed by behavioral and neuropathological analyses. We found that early pridopidine treatment improves motor learning, motor performance, and psychiatric-like phenotypes in YAC128 HD mice. Although no effect on striatal or corpus callosal volumes was observed, RNA-sequencing (RNA-seq) analysis revealed that early pridopidine treatment reverses striatal transcriptional deficits in YAC128 mice, a key pathological feature of HD. Taken together, our study provides further evidence of the neuroprotective effects of pridopidine and supports its continued clinical development for the treatment of HD.

\section{Results}

Early pridopidine treatment improves motor function in YAC128 HD mice. The YAC128 mouse model of HD exhibits motor, cognitive, and psychiatric symptoms characteristic of HD patients and has therefore been used extensively to assess potential therapeutic candidates $(5,20-23)$.

We examined the effect of early pridopidine treatment on animals before disease manifestation (premanifest) (pridopidine administration started at 1.5 months of age and continued until the end of the study) to determine whether improvements in disease-associated phenotypes could be achieved. All mice were tested longitudinally, starting at 2 months of age and ending at 12 months (Figure 1A). 
A Fixed-speed rotarod: motor learning (2 months)

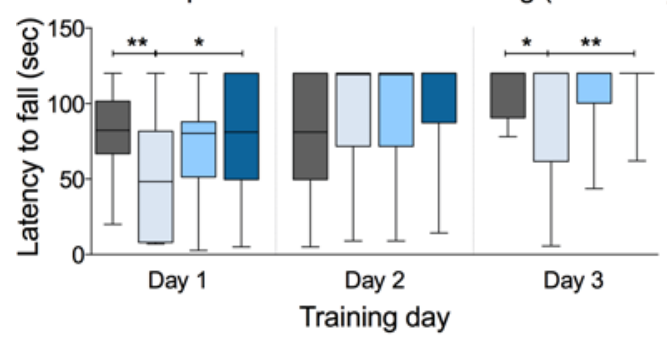

C

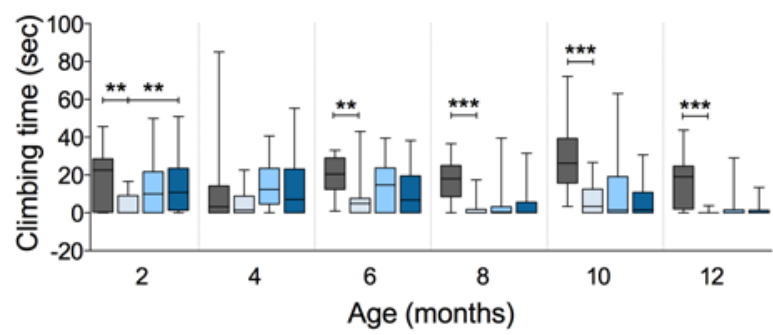

B

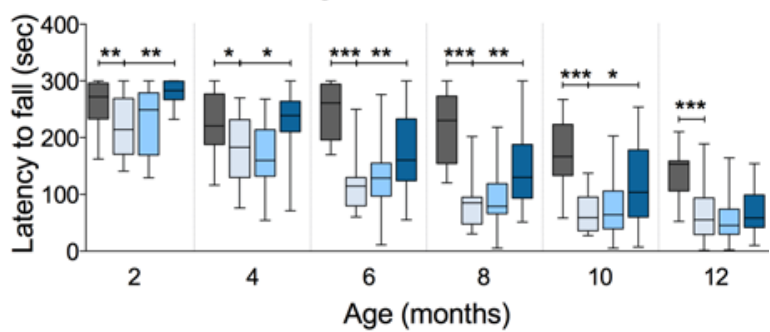

D

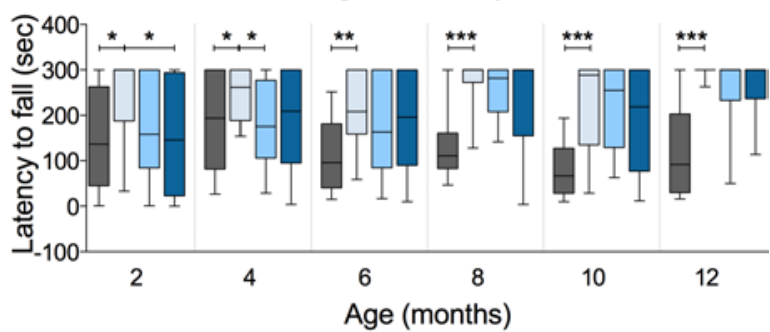

E

Spontaneous activity (12 months)

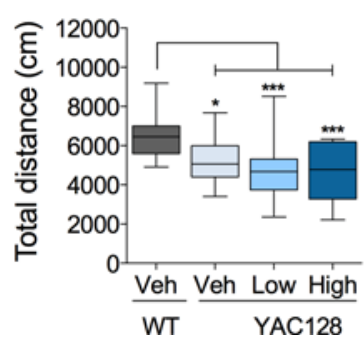

WT-vehicle

YAC128-vehicle

YAC128-low $(10 \mathrm{mg} / \mathrm{kg})$

YAC128-high (30 mg/kg)

Figure 2. Early pridopidine treatment improves motor function in YAC128 HD mice. (A) Vehicle-treated YAC128 HD mice displayed motor learning deficits in the rotarod training task at 2 months of age. High-dose pridopidine improved motor learning by increasing latency to fall in YAC128 HD mice, whereas no effect of low dose was observed. (B) Vehicle-treated YAC128 HD mice exhibited motor deficits in the accelerating rotarod. High-dose pridopidine improved motor performance as early as 2 months of age; improved motor performance was maintained until 10 months. Low-dose pridopidine had no effect on rotarod performance. (C and D) Motor deficits in vehicle-treated YAC128 HD mice were also observed in the climbing test. High-dose pridopidine improved performance in climbing test by increasing climbing time at 2 months of age (C) and decreasing latency to climb at 2 and 4 months of age (D). (E) Vehicle-treated YAC128 HD mice traveled a shorter distance in the spontaneous activity test. Pridopidine treatment (10 and $30 \mathrm{mg} / \mathrm{kg}) \mathrm{did} \mathrm{not} \mathrm{improve} \mathrm{motor}$ deficits in treated YAC128 HD mice. Box-and-whisker plots show median (line within box), 25th and 75th percentile (bounds of box), and minimum and maximum values (bars). $n=11-21$ WT-vehicle, $n=14-19$ YAC128-vehicle, $n=18-20$ YAC128-pridopidine (10 mg $/ \mathrm{kg}$ ), $n=16-20$ YAC128-pridopidine (30 mg/ kg). ${ }^{*} P<0.05,{ }^{* *} P<0.01,{ }^{* *} P<0.001$ by 1 -way ANOVA with Fisher's LSD post-hoc analysis.

Consistent with previous studies, vehicle-treated YAC128 HD mice showed motor learning deficits compared with vehicle-treated WT, as signified by a reduced latency to fall during the rotarod training at 2 months of age (Figure 2A; 1-way ANOVA with Fisher's least significant difference (LSD) post-hoc analysis; $P<0.01$ at day 1 and $P<0.05$ at day 3) (24). YAC128 HD mice treated with the higher dose of pridopidine $(30 \mathrm{mg} / \mathrm{kg})$ displayed motor learning improvements at day 1 and 3 of rotarod training compared with vehicle-treated YAC128 HD mice (Figure 2A; 1-way ANOVA with Fisher's LSD post-hoc analysis; $P$ $<0.05$ at day 1 and $P<0.01$ at day 3$)$. YAC128 HD mice treated with the lower dose performed at the same level as vehicle-treated YAC128 HD mice (Figure 2A; 1-way ANOVA with Fisher's LSD post-hoc analysis; $P=0.085$ at day $1, P=0.999$ at day 2 , and $P=0.055$ at day 3 ). Following motor learning assessment, mice were tested on the accelerating rotarod task in which vehicle-treated YAC128 HD mice showed defective motor performance as early as 2 months of age compared with vehicle-treated WT mice, as reported in previous studies (Figure 2B; 1-way ANOVA with Fisher's LSD post-hoc analysis; $P<0.01$ at 2 months, $P$ $<0.05$ at 4 months, and $P<0.001$ at 6, 8, 10, and 12 months) $(22,24-26)$. Treatment with the higher dose of pridopidine $(30 \mathrm{mg} / \mathrm{kg})$ resulted in motor performance improvements in treated YAC128 HD mice. Such improvements were observed as early as 2 months of age and were maintained until 10 months of 
A

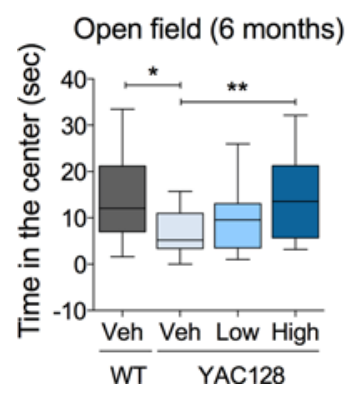

B

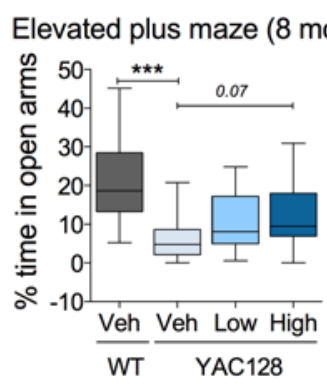

C
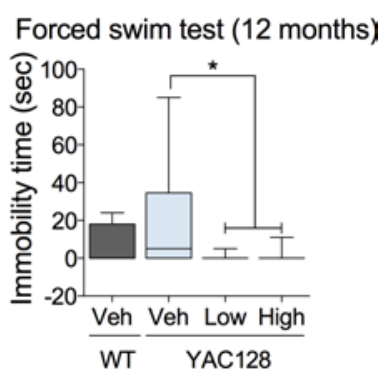

Figure 3. Early pridopidine treatment improves anxiety- and depressive-like phenotypes in YAC128 HD mice. (A and B) Vehicle-treated YAC128 HD mice displayed anxiety-like phenotypes in the open field (A) and elevated plus maze (B). High-dose pridopidine increased the time spent in the center of the arena (A) and in the open arms (B), but no effect of low-dose pridopidine was observed. (C) Vehicle-treated YAC128 HD mice showed a trend toward an increased time spent immobile compared with vehicle-treated WT mice in the forced swim test. Both doses of pridopidine reduced depressive-like behavior. Box-and-whisker plots show median (line within box), 25th and 75th percentile (bounds of box), and minimum and maximum values (bars). (A and $\mathbf{B}$ ) $n=16-17$ WT-vehicle, $n=14-16$ YAC128-vehicle, $n=19-20$ YAC128-pridopidine (10 mg/kg), $n=16-17$ YAC128-pridopidine $(30 \mathrm{mg} / \mathrm{kg}) .{ }^{*} P<0.05,{ }^{* *} P<0.01$, ${ }^{* * *} P<0.001$ by 1-way ANOVA with Fisher's LSD post-hoc analysis. (C) $n=4$ (M) WT-vehicle, $n=8$ (M) YAC128-vehicle, $n=9$ (M) YAC128-pridopidine (10 $\mathrm{mg} / \mathrm{kg}$ ), $n=8$ YAC128-pridopidine (30 mg/kg). ${ }^{*} P<0.05$ by 1-way ANOVA with Fisher's LSD post-hoc analysis; \#\# $P<0.01$ by 2 -tailed Student's $t$ test. Veh, vehicle; Pri, pridopidine; Low, $10 \mathrm{mg} / \mathrm{kg}$; High, $30 \mathrm{mg} / \mathrm{kg}$; M, males.

age (Figure 2B, 1-way ANOVA with Fisher's LSD post-hoc analysis; $P<0.01$ at 2, 6, and 8 months and $P<0.05$ at 4 and 10 months). However, the effect of pridopidine treatment ( $30 \mathrm{mg} / \mathrm{kg}$ ) gradually reduced over time and, by 12 months of age, treated YAC128 HD mice displayed motor deficits, as signified by a shorter latency to fall, performing at the same level as vehicle-treated YAC128 HD mice (Figure 2B; 1-way ANOVA with Fisher's LSD post-hoc analysis; $P=0.778$ ). No effect of the lower dose of pridopidine was observed in treated YAC128 HD mice in this task (Figure 2B; 1-way ANOVA with Fisher's LSD post-hoc analysis; $P>0.05$ compared with vehicle-treated YAC128 HD mice).

To explore motor function further, mice were also evaluated on the climbing test. Consistent with the results obtained in the rotarod task, vehicle-treated YAC128 HD mice spent less time climbing (Figure 2C; 1-way ANOVA with Fisher's LSD post-hoc analysis; $P<0.05$ at 2 months, $P=0.0504$ at 4 months, $P<$ 0.01 at 6 months, and $P<0.001$ at 8,10 , and 12 months) and had an increased latency to climb (Figure 2D; 1 -way ANOVA with Fisher's LSD post-hoc analysis; $P<0.05$ at 2 and 4 months, $P<0.01$ at 6 months, and $P<0.001$ at 8,10 , and 12 months) showing motor deficits as early as 2 months of age. Improvements were observed in YAC128 HD mice treated with pridopidine early on, as shown by an increased time spent climbing at 2 months in mice treated with the high dose (Figure 2C; 1-way ANOVA with Fisher's LSD post-hoc analysis; $P<0.01$ at 2 months) and a shorter latency to climb (Figure 2D; 1-way ANOVA with Fisher's LSD post-hoc analysis; $P<0.05$ at 2 and 4 months for both doses) at 2 and 4 months in mice treated with the high and low dose, respectively, but not at later time points.

At 12 months of age, mice were assessed in the spontaneous activity test. Vehicle-treated YAC128 HD mice traveled a shorter distance compared with vehicle-treated WT mice over a 30-minute test, indicating the presence of motor deficits (Figure 2E; 1-way ANOVA with Fisher's LSD post-hoc analysis; $P<0.05$ ). No effect of pridopidine treatment was observed in either of the treated groups of YAC128 HD mice (Figure 2E; 1-way ANOVA with Fisher's LSD post-hoc analysis; $P=0.361$ for low dose and $P=0.158$ for high dose compared with vehicle-treated YAC128 HD mice).

Altogether, our results indicate that early administration of pridopidine $(30 \mathrm{mg} / \mathrm{kg})$ in premanifest YAC128 HD mice improves motor learning phenotypes and delays the appearance of motor deficits and that such effects are disease-specific since the performance of WT mice treated with the high dose of pridopidine $(30 \mathrm{mg} / \mathrm{kg}$ ) was largely unaffected (Supplemental Figure 1; supplemental material available online with this article; https://doi.org/10.1172/jci.insight.95665DS1).

Early pridopidine treatment improves psychiatric-like phenotypes in YAC128 HD mice. The YAC128 mouse model of HD also presents psychiatric abnormalities $(5,27)$.To evaluate the effect of early pridopidine treatment on HD-related psychiatric phenotypes, mice were assessed on anxiety- and depressive-like behavioral tests. We found that vehicle-treated YAC128 HD mice displayed anxiety-like phenotypes in the open-field (OF) and elevated plus maze (EPM) tests at 6 and 8 months of age, respectively, compared with vehicle-treated WT 
mice (Figure 3, A and B; 1-way ANOVA with Fisher's LSD post-hoc analysis; $P<0.05$ for $\mathrm{OF}$ and $P<0.001$ for EPM). YAC128 HD mice treated with the high dose of pridopidine spent more time in the center of the arena in the OF as well as in the open arms of the EPM compared with vehicle-treated YAC128 HD mice, indicative of a reduced anxiety-like phenotype (Figure 3, A and B; 1-way ANOVA with Fisher's LSD posthoc analysis; $P<0.01$ for OF and $P=0.07$ for EPM; paired 2-tailed Student's $t$ test; $P<0.01$ for EPM). However, no effect of the lower dose of pridopidine $(10 \mathrm{mg} / \mathrm{kg}$ ) was observed in treated YAC128 HD mice (Figure 3, A and B; 1-way ANOVA with Fisher's LSD post-hoc analysis; $P=0.407$ for OF and $P=0.148$ for EPM).

At 12 months of age, male mice were evaluated in the forced swim test (FST) to assess depressive-like phenotypes. The time spent immobile instead of swimming was greater in the vehicle-treated YAC128 HD male mice compared with vehicle-treated WT mice, although the difference did not reach statistical significance (Figure 3C; 1-way ANOVA with Fisher's LSD post-hoc analysis; $P=0.218$ ). Interestingly, in this test, both doses of pridopidine reduced the depressive-like phenotype observed in YAC128 HD male mice as shown by a reduction in the time spent immobile (Figure 3C; 1-way ANOVA with Fisher's LSD post-hoc analysis; $P<0.05$ for both pridopidine doses).

These findings that early administration of pridopidine leads to anxiolytic $(30 \mathrm{mg} / \mathrm{kg})$ and antidepressant $(10$ and $30 \mathrm{mg} / \mathrm{kg}$ ) effects in YAC128 HD but not WT (30 mg/kg; Supplemental Figure 1) mice suggest that pridopidine may be of potential value for the treatment of $\mathrm{HD}$-associated psychiatric symptoms.

Effect of late pridopidine treatment on manifest YAC128 HD mice. We then examined the effect of pridopidine treatment on animals with manifest disease. YAC128 HD mice were assessed for cognitive, motor, and psychiatric function between 9.5 and 10 months of age (Figure 1B). Motor learning deficits were observed in vehicle-treated YAC128 HD mice compared with vehicle-treated WT mice, as shown by a decreased latency to fall in the rotarod training task (Supplemental Figure 2A; 1-way ANOVA with Fisher's LSD post-hoc analysis; $P<0.05$ on day 2 and $P<0.01$ on days 1,3 , and 4 compared with vehicle-WT mice). Pridopidine treatment did not improve motor learning deficits in treated YAC128 HD mice (Supplemental Figure 1A; 1-way ANOVA with Fisher's LSD post-hoc analysis; NS on day 1-4 compared with vehicle-YAC128 HD mice). Next, motor function was assessed on the accelerating rotarod test. Motor performance deficits were observed in vehicle-treated YAC128 HD mice compared with vehicle-treated WT mice (Supplemental Figure 2B; 1-way ANOVA with Fisher's LSD post-hoc analysis; $P<0.001$ ), but these were also not improved by pridopidine treatment in YAC128 HD mice (Supplemental Figure 2B; 1-way ANOVA with Fisher's LSD post-hoc analysis; $P<0.001$ compared with vehicle-treated YAC128).

To evaluate the effect of pridopidine on psychiatric function, mice were assessed with anxiety- and depressive-like behavioral tests. At 10 months of age, vehicle-treated YAC128 HD mice did not exhibit anxiety-like phenotypes in OF and EPM (Supplemental Figure 2, C and D; 1-way ANOVA with Fisher's LSD post-hoc analysis; $P=0.314$ in $\mathrm{OF}$ and $P=0.166$ in EPM) but displayed a depressive-like phenotype in the FST (Supplemental Figure 2E, 1-way ANOVA with Fisher's LSD post-hoc analysis; $P<0.05$ ). Although pridopidine treatment had no effect on anxiety-like phenotypes (Supplemental Figure 2, C and D; 1-way ANOVA with Fisher's LSD post-hoc analysis; $P=0.357$ compared with vehicle-treated YAC128 in OF, $P=$ 0.63 vehicle-treated YAC128 in EPM), it improved depressive-like phenotypes in treated YAC128 HD mice in the FST (Supplemental Figure 2E; 1-way ANOVA with Fisher's LSD post-hoc analysis; $P<0.01$ compared with vehicle-treated YAC128). Our data suggest that late administration of pridopidine in manifest YAC128 HD mice may be efficacious to treat depressive-like phenotypes at late stages of HD.

Effect of early pridopidine treatment on HD-related neuropathology in YAC128 HD mice. Given that improvements in behavioral outcomes were mainly observed in animals that received early pridopidine treatment, we decided to evaluate pridopidine's efficacy on HD-related neuropathology in this particular cohort. Striatal atrophy and white matter abnormalities are neuropathological features observed in patients with HD that have also been described in YAC128 HD mice $(22,28,29)$. To assess whether pridopidine could also have therapeutic effects on HD-related neuropathology, we measured striatal and corpus callosum (CC) volume by structural MRI. At 12 months of age, vehicle-treated YAC128 HD mice displayed decreased striatal and CC volume compared with vehicle-treated WT mice (Figure 4, A and B; 1-way ANOVA with Fisher's LSD post-hoc analysis; $P<0.001$ for striatum and CC). However, no effect of pridopidine treatment was observed in these two measures in treated YAC128 HD mice (Figure 4, A and B; 1-way ANOVA with Fisher's LSD post-hoc analysis; $P>0.05$ for both doses). The effect of pridopidine treatment on striatal and $C C$ volume at earlier time points ( 7 and 10 months of age) was also assessed (Supplemental Figure 3, A-D). At these time points, vehicle-treated YAC128 HD mice dis- 
A
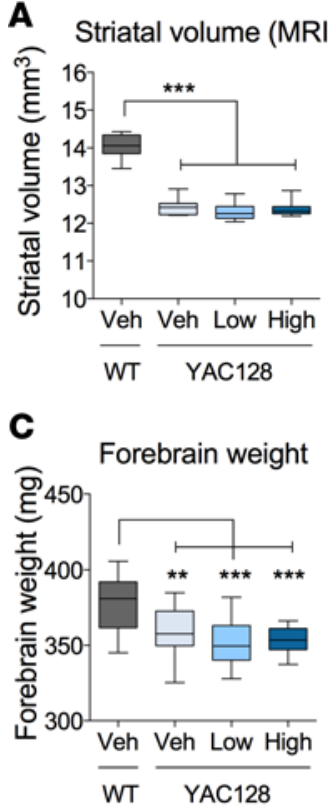

$\mathbf{F}$

DARPP32 (OD)

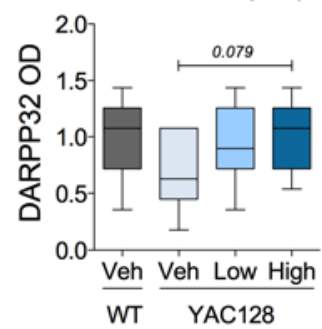

I

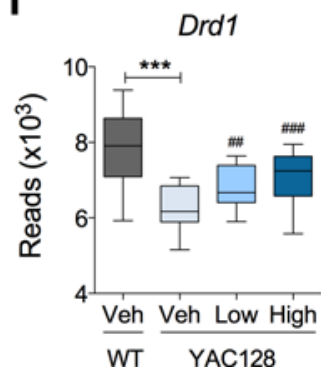

B

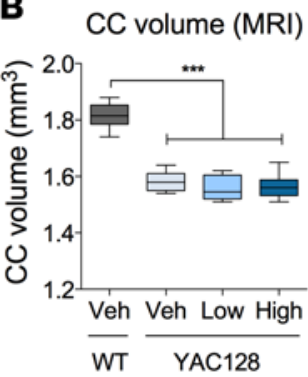

D

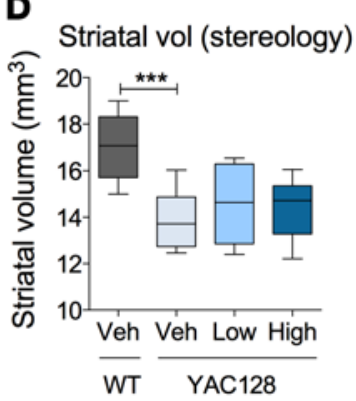

G

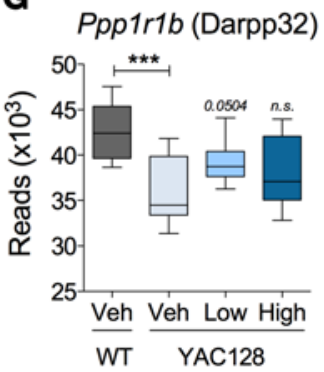

$\mathbf{J}$

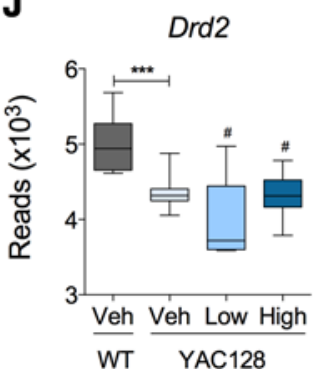

E

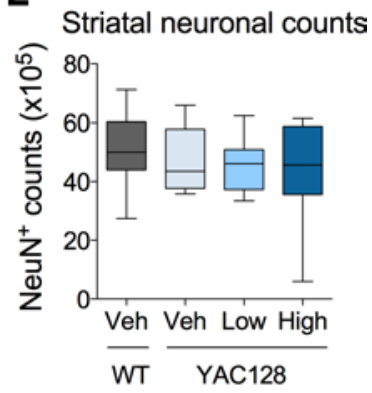

H

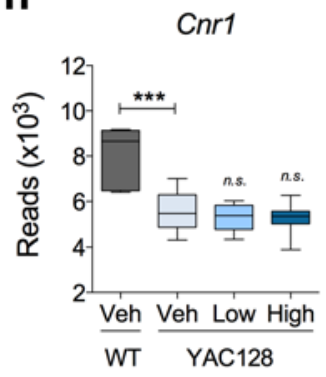

$\mathbf{K}$

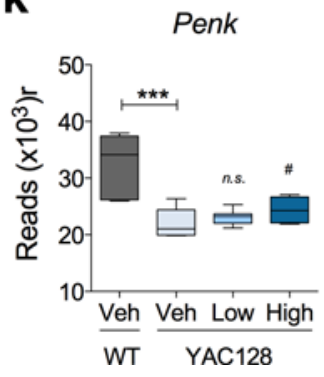

Figure 4. Effect of early pridopidine treatment on neuropathology in YAC128 HD mice at 12 months of age. (A and $\mathbf{B}$ ) Analysis of HD-related pathology by structural MRI revealed decreased striatal (A) and CC (B) volume in vehicle-treated YAC28 HD mice. No effect on striatal and CC volume were observed following pridopidine treatment. (C and D) Vehicle-treated YAC128 HD mice showed decreased forebrain weight (C) and decreased striatal volume (stereological assessment) (D). No effect of pridopidine treatment was observed in both measures in YAC128 HD mice. (E) Investigation of striatal neuronal loss showed no differences in estimated number of striatal counts between genotypes or between treatment groups. (F) A trend toward a decrease in DARPP32 OD was observed in vehicle-treated YAC128 mice, whereas high-dose pridopidine showed a trend toward an increment. No effect was observed with low-dose pridopidine. (G-K) Transcriptome profiling revealed a reduction of reads in striatal-enriched genes, such as Ppp1r1b (Darpp32) (G), Cnr1 (H), Drd1 (I), Drd2 (J), and Penk (K) in vehicle-treated YAC128 mice at 11 months of age. High-dose pridopidine reversed $\operatorname{Drd1}(\mathbf{H}), \operatorname{Drd} 2$ (J), and Penk (K) transcriptional deficits, whereas the low dose reversed Ppp1r1b (Darpp32) (G), Drd1 (I) and $\operatorname{Drd2}(\mathrm{J})$. Pridopidine had no effect on $\mathrm{Cnr1}$ reads at either dose (H). Box-and-whisker plots show median (line within box), 25th and 75th percentile (bounds of box), and minimum and maximum values (bars). (A, B, and D-F) $n=7-10$ WT-vehicle, $n=6-9$ YAC128-vehicle, $n=8-9$ YAC128-pridopidine $(10 \mathrm{mg} / \mathrm{kg}), n=$ 8-11 YAC128-pridopidine ( $30 \mathrm{mg} / \mathrm{kg}) .{ }^{* * *} P<0.001$ by 1-way ANOVA with Fisher's LSD post-hoc analysis. (C) $n=12$ WT-vehicle, $n=18$ YAC128-vehicle, $n=19$ YAC128-pridopidine (10 mg/kg), $n=17$ YAC128-pridopidine $(30 \mathrm{mg} / \mathrm{kg}) .{ }^{* *} P<0.001$ by 1-way ANOVA with Fisher's LSD post-hoc analysis. (G-K) $n=6$ WT-vehicle, $n=9$ YAC128-vehicle, $n=8$ YAC128-pridopidine $(10 \mathrm{mg} / \mathrm{kg}), n=8$ YAC128-pridopidine (30 $\mathrm{mg} / \mathrm{kg}$ ). ${ }^{* * *} P<0.001$ by limma; ${ }^{*} P<0.05,{ }^{\# \#} P<$ $0.01,{ }^{\# \# P} P 0.001$ (compared with vehicle-treated YAC128 HD mice) by limma. CC, corpus callosum; Vol, volume; Veh, vehicle; Pri, pridopidine; Low, $10 \mathrm{mg} /$ kg; High, 30 mg/kg; Ppp1r1b, protein phosphatase 1 regulatory subunit $1 \mathrm{~B} ;$; $C n r 1$, cannabinoid receptor 1 ; Drd1, dopamine receptor 1; $\operatorname{Drd2}$, dopamine receptor 2; Penk, proenkephalin.

played striatal and CC atrophy compared with vehicle-treated WT mice (Supplemental Figure 3, A-D; 1-way ANOVA with Fisher's LSD post-hoc analysis; $P<0.001$ ); however, pridopidine treatment did not rescue the atrophy observed in YAC128 HD mice (Supplemental Figure 3, A-D; 1-way ANOVA with Fisher's LSD post-hoc analysis; $P>0.05$ compared with vehicle-treated YAC128 HD mice).

Following structural MRI analysis, mice were perfused and brains were examined by histological and stereological methods. As expected based on previous results (26), vehicle-treated YAC128 HD mice exhibited reduced forebrain weight compared with vehicle-treated WT mice (Figure 4C; 1-way ANOVA with Fisher's LSD post-hoc analysis; $P<0.001$ ). Pridopidine treatment had no effect on forebrain weight in treated YAC128 HD mice (Figure 4C; 1-way ANOVA with Fisher's LSD post-hoc analysis; $P>0.05$ for both doses of pridopidine compared with vehicle-treated YAC128 HD mice). Subsequently, brains were coronally sectioned and stained with NeuN, a neuronal nuclear marker, to determine striatal volume and striatal neuronal loss by stereological assessment. Consistent with the results we obtained by structural MRI, vehicle-treated YAC128 HD mice displayed decreased striatal volume compared with vehicle-treated WT mice (Figure 4D; 
1-way ANOVA with Fisher's LSD post-hoc analysis; $P<0.001$ ); however, this phenotype was not rescued with pridopidine treatment (Figure 4D; 1-way ANOVA with Fisher's LSD post-hoc analysis; $P>0.05$ for both doses of pridopidine compared with vehicle-treated YAC128 HD mice). Because striatal atrophy can be accompanied by striatal neuronal loss (26), we also estimated the total number of striatal neurons. Stereological counts of NeuN-positive neurons in the striata revealed no significant differences between vehicle-treated YAC128 HD and WT mice (Figure 4E; 1-way ANOVA with Fisher's LSD post-hoc analysis; $P>0.05$ ) or between pridopidine- and vehicle-treated YAC128 HD mice (Figure 4E; 1-way ANOVA with Fisher's LSD post-hoc analysis; $P>0.05$ for both doses of pridopidine). We further assessed DARPP32 expression in medium-sized spiny neurons by quantification of DARPP32 immunoreactivity at 12 months of age. Although reduced expression of DARPP32 has been described in YAC128 HD mice (21), we only detected a slight reduction in $\mathrm{OD}$ in vehicle-treated YAC128 HD mice compared with vehicle-treated WT mice, which did not reach statistical significance (Figure 4F; 1-way ANOVA with Fisher's LSD post-hoc analysis; $P=0.113$ ). Treatment with the high dose of pridopidine resulted in a slight increment in OD in treated YAC128 HD mice, although this difference was not statistically significant (Figure 4F; 1-way ANOVA with Fisher's LSD post-hoc analysis; $P=0.079$ compared with vehicle-treated YAC128 HD mice). No effect of the low dose of pridopidine was observed (Figure 4F; 1-way ANOVA with Fisher's LSD post-hoc analysis; $P=0.147$ compared with vehicle-treated YAC128 HD mice). Our results indicate that early administration of pridopidine, starting before manifestation of disease phenotypes in YAC128 HD mice at the doses used in this study (10 and $30 \mathrm{mg} / \mathrm{kg}$ ), is not sufficient to rescue HD-related neuropathology in YAC128 HD mice.

Early pridopidine treatment reverses transcriptional deficits in YAC128 HD mice. To better understand the mechanism of action of early pridopidine treatment, we performed RNA-seq analysis to investigate the transcriptional profile of the mouse striatum at 11 months of age.

Since transcriptional dysregulation is a well-characterized feature of $\operatorname{HD}(30,31)$, we first compared RNA-seq data between vehicle-treated WT and YAC128 HD mice and found 1,346 differentially expressed genes (DEGs) with adjusted $P(\operatorname{adj} . P$ ) values of less than 0.05 , for which expression was significantly changed in the striatum between both genotypes (Figure 5A). Of these DEGs, 788 genes were downregulated (Figure 5B) and 558 genes were upregulated under disease conditions (Supplemental Figure 4).

Given that pridopidine treatment improved HD symptoms but failed to rescue striatal or corpus callosal atrophy, we asked whether early pridopidine treatment could influence the health of striatal neurons. We therefore investigated the effect of pridopidine treatment on 5 striatally enriched genes known to be specifically downregulated with disease progression in HD, namely protein phosphatase 1 regulatory inhibitor subunit 1B (Ppp1r1b or Darpp32), cannabinoid receptor 1 (Cnr1), dopamine receptors D1 and D2 (Drd1 and Drd2, respectively), and proenkephalin (Penk) (24). As expected, all 5 genes showed a reduction in the number of reads in vehicle-treated YAC128 HD mice compared with vehicle-treated WT mice (Figure 4, G-K; limma; adj. $P<0.001$ for all 5 genes). Interestingly, dose- and gene-specific effects of pridopidine treatment were observed on the transcriptome profile of striatal-enriched genes. Both doses of pridopidine reversed Drd1 deficits in treated YAC128 HD mice (Figure 4I; limma; $P<0.01$ for low doses of pridopidine and $P<0.001$ for high doses of pridopidine compared with vehicle-treated YAC128 HD mice), whereas only the high dose reversed Drd2 deficits (Figure 4J; limma; $P<0.05$ compared with vehicle-treated YAC128 HD mice). On the contrary, the low dose of pridopidine significantly decreased Drd2 reads in treated YAC128 HD mice (Figure 4J; limma; $P<0.05$ compared with vehicle-treated YAC128 HD mice). Penk reads were also increased in the striata of treated YAC128 HD mice after treatment with the high dose $(30 \mathrm{mg} / \mathrm{kg})$ of pridopidine (Figure 4K; limma; $P<0.05$ for Penk high dose compared with vehicle-treated YAC128 HD mice). However, pridopidine was not able to reverse Ppp1r1b and Cnr1 deficits in treated YAC128 HD mice at the doses used in this study (Figure 4, G and H; limma; $P>0.05$ for both doses of pridopidine compared with vehicle-treated YAC128 HD mice).

To gain further insight into the mechanism of pridopidine's action, we performed an unbiased genomewide transcriptional analysis for genes that were upregulated or downregulated in YAC128 HD mice and that were oppositely changed by either dose of pridopidine treatment (adj. $P<0.05$, opposite fold change). Overlap analysis revealed 74 significant DEGs (adj. $P<0.05$ ), for which the number of reads was downregulated in vehicle-treated YAC128 HD mice and upregulated following pridopidine treatment $(10 \mathrm{mg} / \mathrm{kg}$ and/or $30 \mathrm{mg} / \mathrm{kg}$ ) (Figure 5, B and C). Of those, 31 genes were common to all three groups (Figure 5B). When we looked for genes that were upregulated in vehicle-treated YAC128 HD mice and downregulated 
A

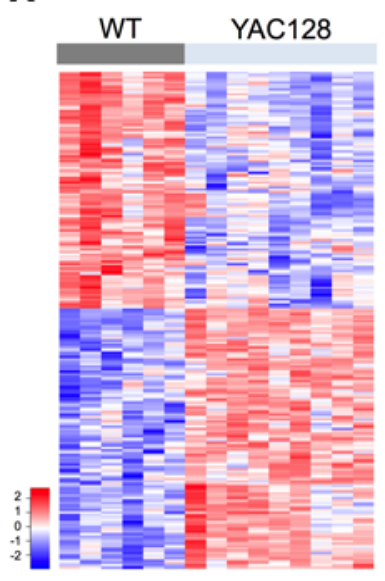

B

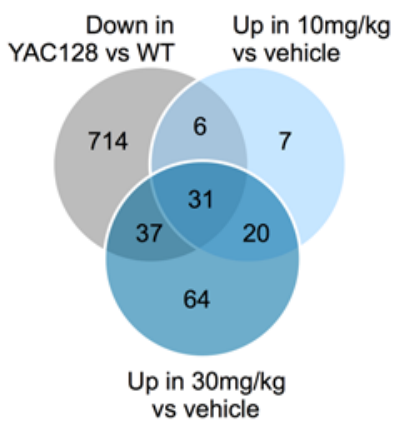

C

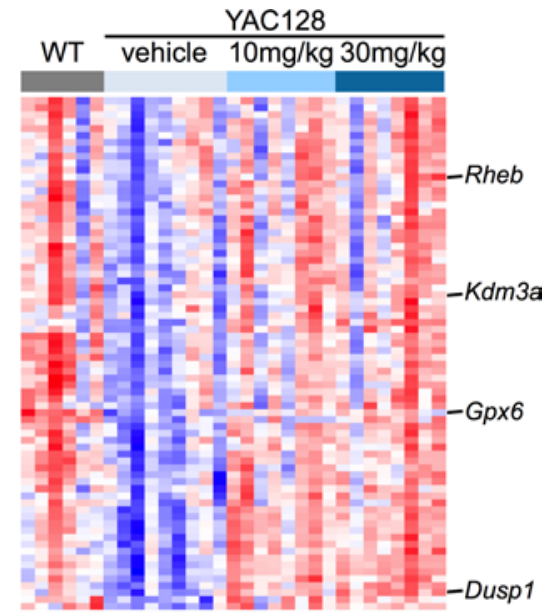

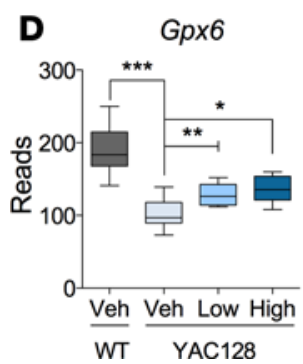
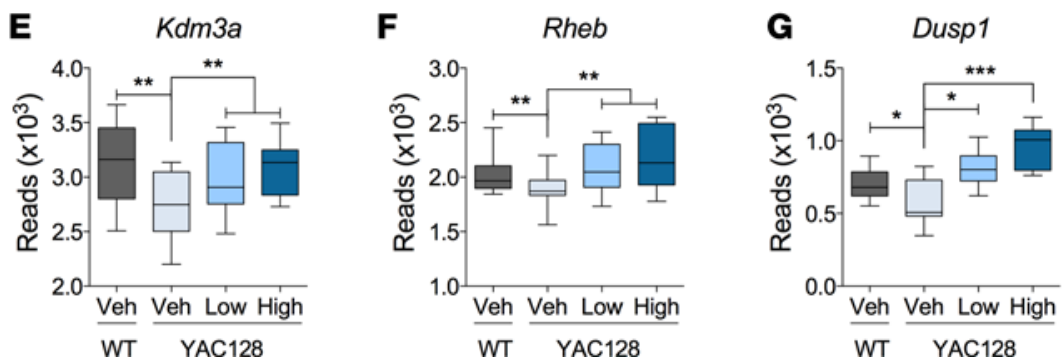

Figure 5. Pridopidine treatment reverses transcriptional deficits in the striata of YAC128 HD mice. (A) Heatmap showing 208 RNA-seq differentially expressed genes with adj. $P<0.05$ and $|\log F C|>0.5$ between vehicle-treated WT and YAC128 HD mice. Red indicates relative increased expression and blue indicates relative decreased expression. (B) Overlap analysis of striatal genes downregulated in vehicle-treated YAC128 HD mice compared with vehicle-treated WT mice and striatal genes upregulated in the striata of pridopidine-treated YAC128 HD mice. (C) Heatmap displaying the 74 genes that showed opposite differential expression between vehicle-treated YAC128 HD mice compared with pridopidine-treated (10 and $30 \mathrm{mg} / \mathrm{kg}$ ) YAC128 HD mice. (D and E) RNA-seq analysis revealed downregulation of $G p \times 6(\mathbf{D})$ and $K d m 3 a(\mathbf{E})$ genes in vehicle-treated YAC128 HD mice compared with vehicle-treated WT mice. Both doses of pridopidine increased the number of $G p \times 6(\mathbf{D}), K d m 3 a(\mathbf{E})$, Rheb (F), and Dusp1 (C) reads. (D-C) Box-and-whisker plots show median (line within box), 25th and 75th percentile (bounds of box), and minimum and maximum values (bars). $n=6$ WT-vehicle, $n=9$ YAC128-vehicle, $n=8$ YAC128-pridopidine (10 mg/kg), $n=8$ YAC128-pridopidine (30 mg/kg). ${ }^{*} P<0.05$, ${ }^{* *} P<0.01,{ }^{* *} P<0.001$ by limma. Veh, vehicle; Pri, pridopidine; Low, $10 \mathrm{mg} / \mathrm{kg} ;$ High, 30 $\mathrm{mg} / \mathrm{kg}$; Gpx6, glutathione peroxidase 6; kdm3a, lysine-specific demethylase 3A; Rheb, Ras homolog enriched in brain; Dusp1, dual specificity phosphatase 1.

following pridopidine treatment, overlap analysis identified 10 genes that were downregulated by pridopidine that were not shared between both doses of pridopidine ( 2 genes were downregulated by $10 \mathrm{mg} / \mathrm{kg}$ and 8 different genes were downregulated by $30 \mathrm{mg} / \mathrm{kg}$ ) (Supplemental Figure 4).

Close examination of the list of 74 genes that were transcriptionally reversed by pridopidine treatment identified a number of genes previously implicated in $\mathrm{HD}$, including Gpx6, Kdm3a, Rheb, and Dusp 1 (Figure 5C). These genes were downregulated in vehicle-treated YAC128 HD mice (Figure 5, D-G; limma; adj. $P<$ 0.001 for Gpx6, adj. $P<0.01 \mathrm{Kdm} 3 a$ and Rheb, and adj. $P<0.05$ for Dusp 1 ), and this reduction was reversed by both doses of pridopidine as signified by a larger number of reads in pridopidine-treated YAC128 HD mice (Figure 5, D-G; limma; $P<0.01$ for Gpx6, Kdm3a, and Rheb and adj. $P<0.01$ for Dusp 1 for low dose compared with vehicle-treated YAC128 HD mice; adj. $P<0.05$ for Gpx6, adj. $P<0.01$ for Kdm3a and Rheb, and adj. $P<0.001$ for Dusp 1 for high dose compared with vehicle-treated YAC128 HD mice). Altogether, our results from RNA-seq analysis revealed that pridopidine treatment reverses striatal transcriptional deficits of genes implicated in $\mathrm{HD}$, suggesting a beneficial effect of pridopidine at a molecular level.

We next explored the possible biological basis for the greater behavioral improvements seen in the highdose $(30 \mathrm{mg} / \mathrm{kg}$ ) group relative to the low-dose $(10 \mathrm{mg} / \mathrm{kg}$ ) group by comparing the DEGs (adj. $P<0.05$; both upregulated and downregulated) seen in each pridopidine group relative to the vehicle-treated YAC128 HD control group (Figure 6A). Functional annotation of DEGs common to both the $10 \mathrm{mg} / \mathrm{kg}$ and $30 \mathrm{mg} /$ kg groups using Enrichr (32) revealed 9 significantly (top 6 shown) enriched COMPARTMENTS (33) cellular component categories, including Bcl-2 (adj. $P=0.003$ ) and NF- $\mathrm{kB}$ (adj. $P=0.036$ ) complex members, yet no gene ontology (GO) cellular component categories were found to be enriched (Figure 6B and Supplemental 
A

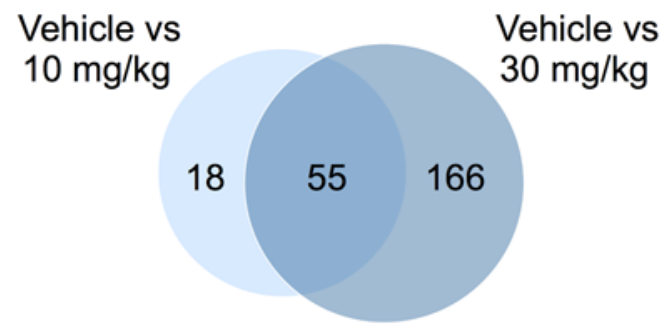

B

\section{Common to 10 and $30 \mathrm{mg} / \mathrm{kg}$}

$\mathrm{p}=0.05$

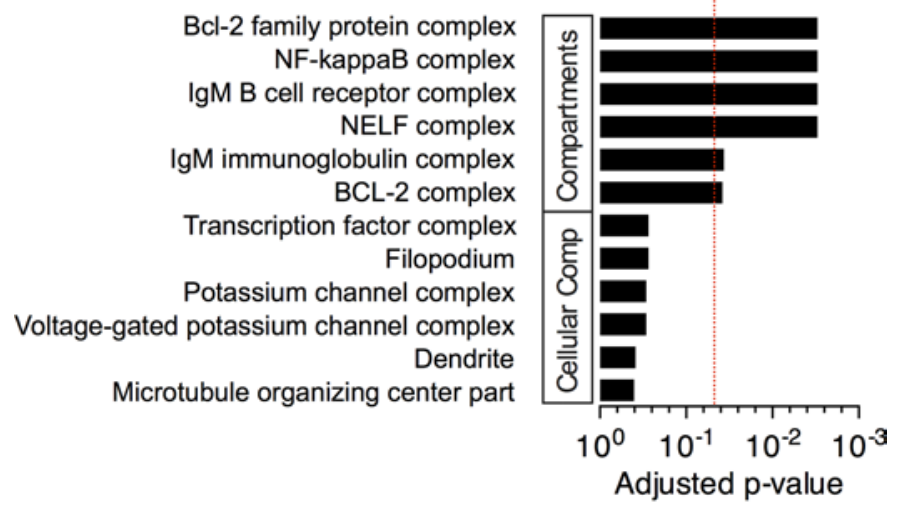

C
Figure 6. Functional annotation of DEGs in the striata of YAC128 HD mice. (A) Overlap in DEGs (relative to YAC128-vehicle) between the $10 \mathrm{mg} /$ $\mathrm{kg}$ and $30 \mathrm{mg} / \mathrm{kg}$ pridopidine groups. (B and $\mathbf{C}$ ) Functional annotation of DEGs common to both 10 and $30 \mathrm{mg} / \mathrm{kg}$ (B) or specific to $30 \mathrm{mg} / \mathrm{kg}$ (C) enriched in COMPARTMENTS cellular component categories and gene ontology cellular component categories.

Table 9). In contrast, DEGs specific to the $30 \mathrm{mg} / \mathrm{kg}$ group were enriched for 7 COMPARTMENTS cellular component categories, such as synapse (adj. $P=0.003$ ), synaptic vesicle membrane (adj. $P=0.025$ ), and neuron projection (adj. $P=0.037$ ) as well as the GO cellular component synapse category (adj. $P=0.001$ ) (Figure 6C and Supplemental Table 10).

To further investigate pridopidine dose effects, we examined DEGs (adj. $P<0.05$ ) using cell type-specific expression analysis (34). Whereas DEGs common to both the $10 \mathrm{mg} / \mathrm{kg}$ and $30 \mathrm{mg} / \mathrm{kg}$ groups were enriched in genes expressed in striatal medium spiny and cortical project neurons (Figure 7A), DEGs specific to the 30 $\mathrm{mg} / \mathrm{kg}$ group were additionally enriched in transcripts expressed in cholinergic neurons (Figure 7B). Inspection of the 19 DEGs annotated as being enriched in cholinergic neurons revealed that, while their pattern of expression is similar between the $10 \mathrm{mg} / \mathrm{kg}$ and 30 $\mathrm{mg} / \mathrm{kg}$ groups, the magnitude of change in level of expression (relative to the YAC128 vehicle group) was dose dependent, i.e., greater in the $30 \mathrm{mg} / \mathrm{kg}$ compared with the $10 \mathrm{mg} / \mathrm{kg}$ group (Figure 7C). Of note, a number of these genes have been previously implicated in HD, such as Cib2 (35), Npas1 (36), St8sia2 (37), and Gng4 (38). Our results suggest that the dose effects seen in the behavioral assays were associated with underlying differential transcriptional patterns and that they further implicate synaptic changes and the cholinergic system in the greater functional improvements seen with the $30 \mathrm{mg} / \mathrm{kg}$ pridopidine dose.

Pridopidine concentration in plasma in mice in the early treatment cohort. At the end of the early treatment study, we determined the plasma-unbound concentration of pridopidine in treated mice. This approach has been used to indirectly estimate the brain-unbound concentration of drugs (39). Blood was collected 30 minutes after dose administration at 11 months of age. As expected, mean pridopidine concentration measured in plasma in the low dose-treated YAC128 HD mice $(2,623 \pm 184.8 \mathrm{ng} / \mathrm{ml}$; mean \pm SEM) was lower than the concentration measured in the high dose-treated YAC128 HD mice $(6,412 \pm 494.1 \mathrm{ng} / \mathrm{ml}$; mean $\pm \mathrm{SEM})$ (Supplemental Figure 5; unpaired 2-tailed $t$ test; $P<0.001$ )

\section{Discussion}

We believe this study represents the first comprehensive preclinical evaluation of the effects of pridopidine, a compound currently under clinical development, on behavioral, neuropathological, and molecular phenotypes in a full-length mouse model of HD.

We show that early treatment with pridopidine results in improvements in motor learning and coordination and in psychiatric-like features in the YAC128 mouse model of HD. The effects of treatment showed dose dependence, with $30 \mathrm{mg} / \mathrm{kg}$ resulting in greater overall benefit compared with the $10 \mathrm{mg} /$ $\mathrm{kg}$ dose. The improvements were seen throughout the disease course, with improved motor performance lasting from 2 to 10 months of age, reduced anxiety-like phenotypes at 6 and 8 months of age, and amelioration of depressive-like behavior at 12 months of age. There was no effect of pridopidine treatment on brain weight or on striatal or CC volume in YAC128 HD mice. In addition, we did not observe 

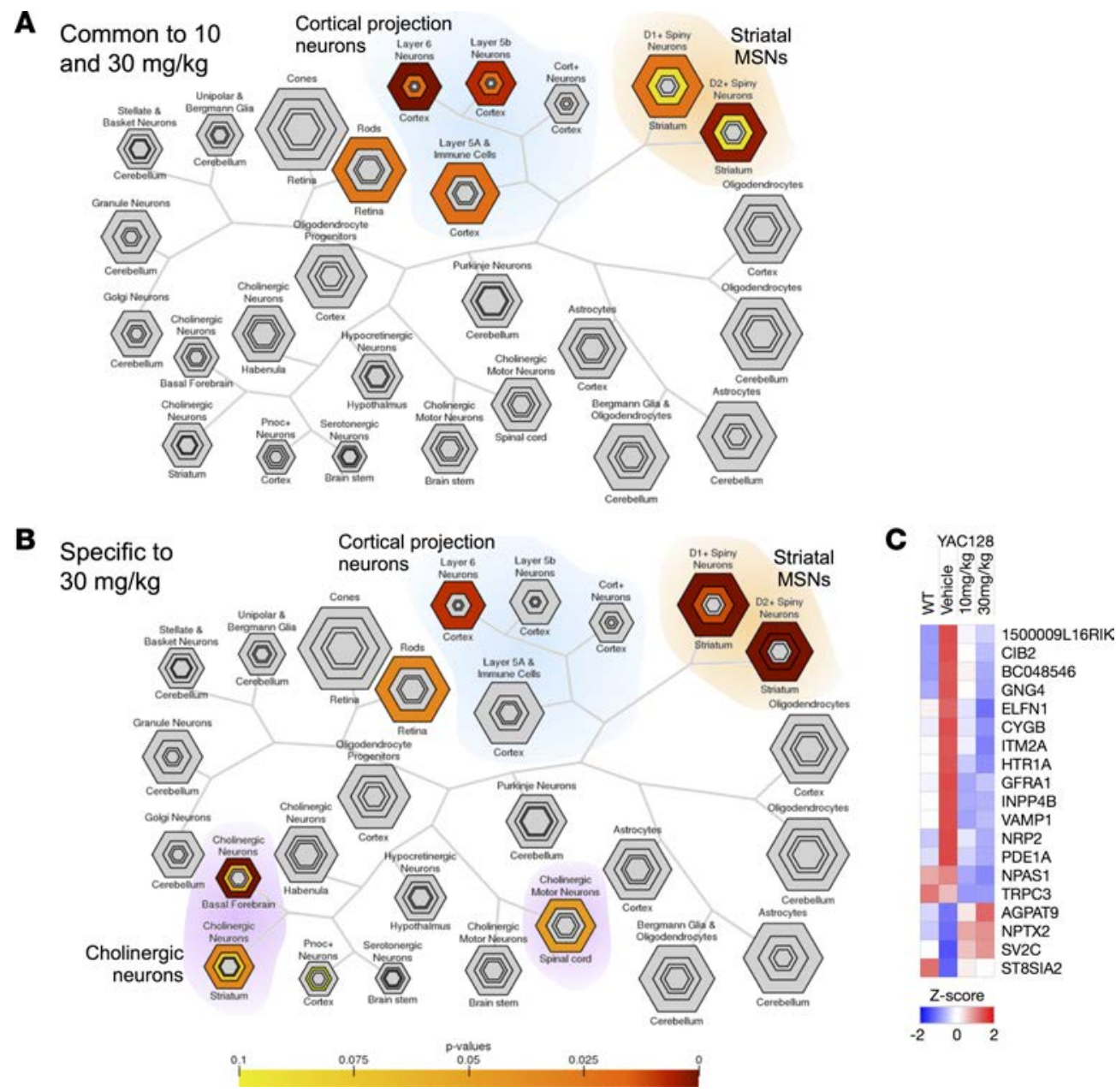

Figure 7. Cell type-specific analysis of DEGs in the striata of YAC128 HD mice. (A and B) Cell type-specific analysis of DEGs common to both the 10 and 30 mg/ $\mathrm{kg}$ pridopidine groups (A) or specific to the $30 \mathrm{mg} / \mathrm{kg}$ pridopidine group (B). (C) Heatmap of gene transcripts enriched in cholinergic neurons specific to the 30 $\mathrm{mg} / \mathrm{kg}$ pridopidine group.

differences in striatal neuronal counts between genotypes or treatment groups. This lack of genotypic difference has been reported previously $(20,26,40)$, suggesting that the change in gross neuronal counts may be susceptible to differences in the experimental designs employed in the different studies. The improvements in behavioral outcomes are not likely to represent acute effects given pridopidine's short half-life and the fact that on test days pridopidine was administered after the behavioral assays were completed. Furthermore, the effects appear to be HD specific, as no effects were seen in treated WT mice. In contrast, when pridopidine was administered to mice at a later time point, when the disease was clearly manifest in terms of both symptomatic and cellular characteristics, the functional benefits of pridopidine were limited, although improvements in depressive-like behavior were noted.

Although the actions of pridopidine had been initially attributed to D2R antagonism, several emerging lines of evidence argue against a purely D2R-based mechanism of action. First, pridopidine exhibits certain effects not typical of D2R antagonists, such as procognitive and prosocial effects (41). Second, pridopidine treatment does not elicit certain behaviors expected of D2R antagonists, such as catalepsy (42). Third, effects of pridopidine on certain behaviors associated with $\mathrm{D} 2 \mathrm{R}$ antagonism, such as the dampening of amphetamine-induced hyperactivity, persist in D2R KO mice, in contrast to typical D2R antagonists, such as haloperidol (43). These observations collectively argue against $\mathrm{D} 2 \mathrm{R}$ being the sole or primary mediator of pridopidine action.

Cumulative evidence instead points toward S1R as a major mediator of pridopidine action at the doses used in current studies of its therapeutic potential. Indeed, in vitro radioligand competition experiments and in vivo PET studies have shown that pridopidine binds to S1R at nanomolar levels and exhibits an approximately 100-fold higher binding affinity to S1R relative to D2R (10). Furthermore, aspects of pridopidine's 
action, such as its procognitive and neuroprotective effects, appear to overlap with those of known S1R agonists (44). With respect to neuroprotection, two recent studies examined the effects of pridopidine on molecular and cellular correlates of neuroprotection and the role of S1R in this process. In the first study, pridopidine was shown to enhance the release of the trophic factor BDNF by a neuronal cell line, and this effect was abolished by pretreatment with the S1R antagonist NE100 (45). A more recent study showed that pridopidine treatment protected against HD-related dendritic spine loss in corticostriatal cocultures (8). Importantly, genetic inactivation of S1R abolished pridopidine's protective effects (8). Combined, these studies provide compelling evidence implicating S1R in pridopidine's mechanism of action and suggest that the relative contribution of pridopidine cognate receptors will likely depend on the dose used.

In this study, the low $(10 \mathrm{mg} / \mathrm{kg})$ dose used is expected to result in $>50 \%$ S1R occupancy and minimal-to-no binding at D2R (M. Geva, unpublished observations). The high (30 mg/kg) dose on the other hand is expected to lead to $>70 \%$ S1R occupancy as well as some D2R binding $(<30 \%)$ (M. Geva, unpublished observations). Thus, it is possible that the greater functional benefits seen with the high relative to the low dose reflect the higher level of S1R occupancy, activity at D2R, or both. Irrespective of the exact target of pridopidine, it is likely that multiple molecular pathways underlie its beneficial effects in YAC128 HD mice. This is supported by the differential effects of pridopidine on depressive versus motor phenotypes. Indeed, whereas late treatment was sufficient to improve the depressive-like behavior of YAC128 HD mice, improvements in motor function required early treatment.

S1R-activating ligands have previously been reported to have antidepressant activity. These effects have been attributed in part to modulation of glutamatergic and serotonergic neurotransmission (46). We have recently shown the activity of monoamine oxidase-A/B, enzymes that mediate the breakdown of monoamine neurotransmitters, to be elevated in models of $\mathrm{HD}$ (47). We have further shown that treatment of YAC128 HD mice with an antagonist of monoamine oxidase A leads to elevated striatal levels of monoamine neurotransmitters (such as serotonin, norepinephrine, and dopamine) and improves affective phenotypes (5). Pridopidine has been shown to elevate levels of norepinephrine, dopamine (striatum and prefrontal cortex), and serotonin (prefrontal cortex only) (48). Interestingly, gene set enrichment analysis revealed that the D1R pathway, as defined in ref. 49 , shows a significant (adj. $P<0.05$ ) enrichment with both the low- and high-pridopidine dose. Thus, the improvements we observe in depressive phenotypes in the YAC128 HD mice following pridopidine treatment may reflect, at least in part, enhanced monoaminergic neurotransmission.

Activation of S1R has been shown to be neuroprotective in a number of experimental paradigms (50). In relation to $\mathrm{HD}$, the S1R agonist, PRE084, was shown to enhance cellular antioxidant defences and to protect against mHTT-induced toxicity in a rat neuronal cell line (18). Using R6/2 HD mice, pridopidine treatment was shown to improve motor function and survival, effects that were associated with increased striatal BDNF and DARPP-32 levels (19). Pridopidine was also found to affect mHTT striatal aggregates in R6/2 mice, a result that parallels the decrease in mHTT aggregates in HeLa cells treated with PRE084 (51). Furthermore, pridopidine was found to protect STHdhQ111 striatal-like cells against serum withdrawal-induced toxicity (19). These results suggest that S1R activation may be neuroprotective in HD.

Although the mechanisms of action underlying the neuroprotective effects of S1R activation are not fully understood, some studies have suggested that such effects may include modulation of kinase activity $(45,52,53)$. As dysregulation of AKT and JNK kinases has been implicated in the pathology of HD (45, $54,55)$, it would be interesting to further investigate whether modulation of kinase activity contributes to the neuroprotective effects of pridopidine in HD mice.

Although pridopidine had no effect on striatal volume or corpus callosal atrophy, the functional improvements observed with pridopidine treatment may reflect beneficial effects on subcellular and transcriptional pathological aspects of HD. This is indeed supported by a recent study using primary corticostriatal cocultures from the YAC128 HD mice (8). Treatment with pridopidine was shown to have synaptoprotective activity, preventing HD-related spine loss. This protective effect was shown to be dependent on S1R activity (8). It has also been postulated that a progressive, dying-back pattern of neuronal degeneration contributes to the manifestations of $\operatorname{HD}(55,56)$. Thus, it is possible that some of pridopidine's beneficial effects are the result of slowing one or more pathological processes underlying axonal pathology. Such effects would not necessarily involve changes in the number of neuronal nuclei and would be consistent with the lack of change in NeuN-positive counts in this study.

Further support for this notion of protective effects of pridopidine on the synaptic or subcellular level is provided by the reversal of a substantial proportion of striatal transcriptional deficits in the pridopi- 
dine-treated YAC128 HD mice. Transcriptional dysregulation is a well-documented pathological feature of $\mathrm{HD}(30,31)$. Our analysis revealed that pridopidine treatment rescued transcriptional deficits in key pathways previously implicated in HD. For example, GPX6 and KDM3A were previously linked to HD in an unbiased synthetic lethal screen in the R6/2 mouse model of HD (57). Gpx6 (glutathione peroxidase 6) belongs to the glutathione peroxidase family and functions in the detoxification of hydrogen peroxidase. Knockdown of GPX6 was shown to lead to loss of striatal neurons expressing mHTT, whereas overexpression of GPX6 resulted in neuronal rescue, as measured by DARPP-32 expression, and improved motor function (57). Similarly, deficits in the levels of the mTORC1 regulator RHEB in YAC128 HD mice were reversed by pridopidine treatment. Increasing RHEB activity was recently shown to ameliorate a number of cellular and molecular deficits in HD mice, including mitochondrial deficits and cholesterol dyshomeostasis (58). Finally, pridopidine treatment rescued deficits in DUSP1, a member of the mitogen-activated protein kinase family of phosphatases recently shown to be protective in animal models of HD (59). Collectively, these findings suggest that the transcriptional deficits reversed by pridopidine treatment may contribute to its beneficial effects in YAC128 HD mice.

Support for synaptoprotective activity of pridopidine is also provided by our analysis of DEGs specific to the $30 \mathrm{mg} / \mathrm{kg}$ pridopidine group, which showed greater improvement in behavioral assays. Functional annotation of the DEGs revealed enrichment for synapse and synaptic vesicle-associated genes. In addition, cell type-specific expression analysis showed that DEGs specific to the $30 \mathrm{mg} / \mathrm{kg}$ pridopidine dose were enriched in genes expressed in cholinergic neurons, suggesting a possible role for these neurons in mediating pridopidine's beneficial effects. Dysfunction of the cholinergic system has been reported to play a role in the pathophysiology of several movement disorders, including HD and Parkinson's disease (13, $60,61)$. Importantly, concordant with our findings, S1R-activating ligands have previously been shown to modulate acetylcholine release and cholinergic neurotransmission and to reverse cognitive deficits resulting from cholinergic dysfunction in animal models of cognitive impairment and amnesia (13).

Four of the DEGs identified in the cell type-specific expression analysis, namely Cib2, Npas1, St8sia2, and Gng4, have been previously linked to HD: Cib2, a calcium and integrin-binding family member, is upregulated in the striata of YAC128 HD mice as well as in a PC12 model of HD (35); levels of Npas1, a neuronal PAS domain protein 1 thought to be involved in chromatin remodelling and transcription, are elevated in the PC12 model of HD (36); St8sia2, a ST8 $\alpha$-N-acetyl-neuraminide $\alpha$-2,8-Sialyltransferase 2 related to ganglioside biosynthesis, has been reported to be decreased in the R6/1 mouse model of HD (37); levels of Gng4, a brain-specific subunit of heterotrimeric G protein suggested to play a role in presynaptic function of kainate receptors $(62,63)$, are elevated in D1 medium spiny neurons of YAC128 HD mice at 13 and 23 months of age (44). Our analysis not only validated these previous findings, but also showed that pridopidine treatment $(30 \mathrm{mg} / \mathrm{kg})$ reverses the HD-related alterations in the levels of these genes.

Along with previous studies demonstrating beneficial effects of S1R ligands in HD models (Table 1), our findings suggest that pridopidine is a promising therapeutic agent for the treatment of $\mathrm{HD}$ that provides beneficial effects in behavioral as well as transcriptional deficits in the YAC128 model of HD. Moreover, we have shown that such beneficial effects depend on the timing of the treatment, with early treatment leading to greater benefit. Our transcriptional analysis supports a synaptoprotective role for pridopidine and provides insights into its mechanisms of action. Taken all together, future clinical trials should consider evaluating the efficacy of pridopidine as early in the course of the illness as possible in order to achieve maximal therapeutic benefits.

\section{Methods}

Animals. Male and female YAC128 HD mice (line 53) expressing a full-length human HTT transgene with $128 \mathrm{CAG}$ repeats, maintained on the FVB/N strain were used. Mice were bred at the Biological Resource Centre (A*STAR) and group housed with littermates of mixed genotype. Animals were maintained under a 12-hour-light cycle (lights on at 09:00) in a clean facility and given free access to food and water.

Administration of pridopidine. Pridopidine was synthesized by Teva Pharmaceutical Industries Ltd. and was dissolved in sterile water. Pridopidine and vehicle were administered daily by oral gavage for 5 days/week for 10.5 months for the early treatment cohort and 8 weeks for the late treatment cohort. Mice received vehicle (sterile water), $10 \mathrm{mg} / \mathrm{kg}$ of pridopidine, or $30 \mathrm{mg} / \mathrm{kg}$ of pridopidine at a volume of $4 \mathrm{ml} /$ $\mathrm{kg}$. Animals were weighed every 2 weeks to ensure the correct dose was maintained. 
Table 1. Summary of the effects of S1R ligands in cellular and mouse models of HD.

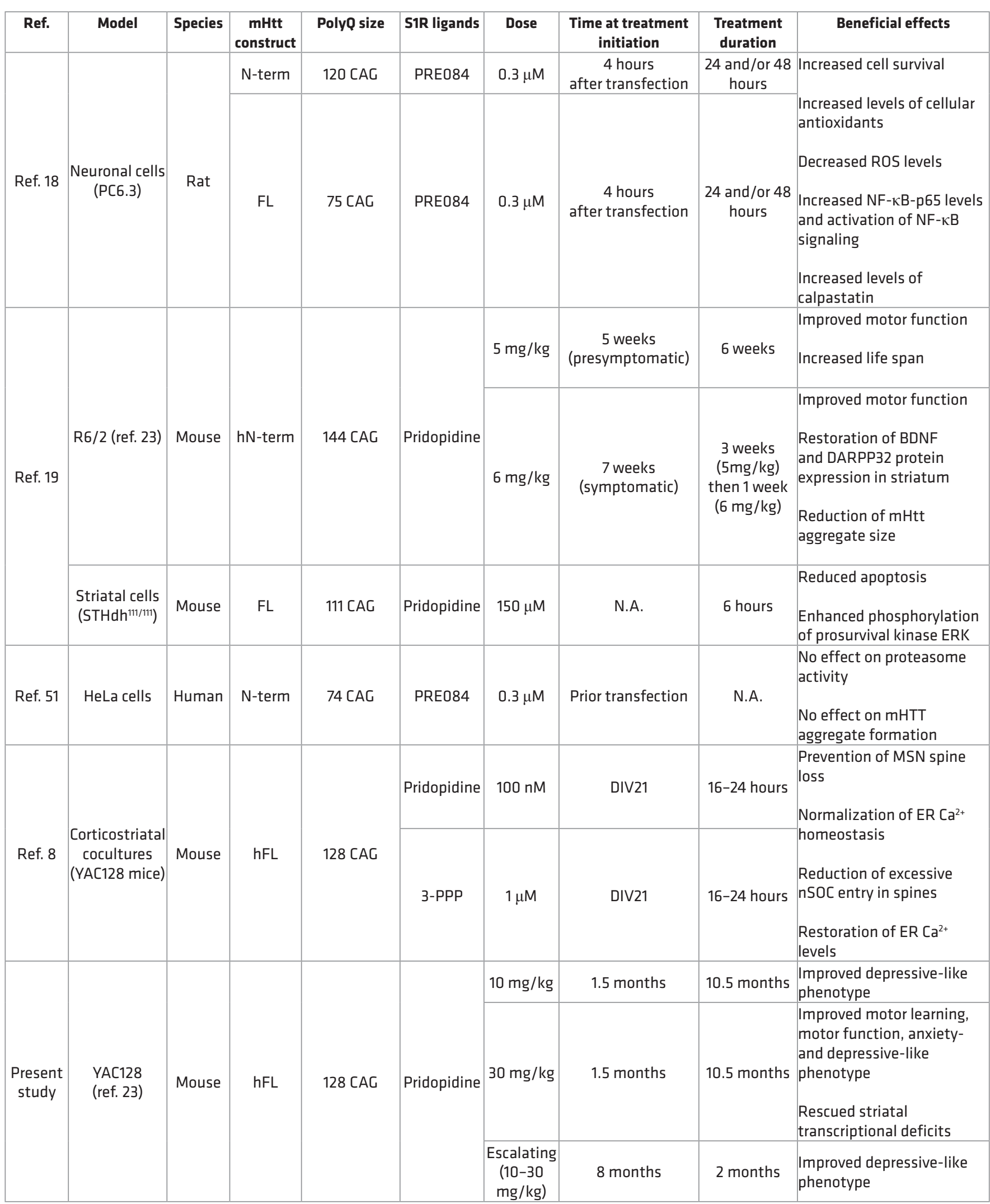

$\mathrm{N}$-term, N-terminal fragment; FL, full length; hN-term, human N-terminal fragment; hFL, human full-length; DIV, day in vitro; BDNF, brain-derived neurotrophic factor; DARPP32, dopamine- and cAMP-regulated phosphoprotein; Ca ${ }^{2+}$, calcium; nSOC, synaptic store-operated calcium; N.A., not applicable. 
Study design. For early treatment cohorts, pridopidine was administered to animals (two cohorts) in the early stages of disease (1.5 months of age). Mice were divided into four groups. Two groups of YAC128 HD mice received pridopidine at a dose of 10 or $30 \mathrm{mg} / \mathrm{kg}$, whereas the remaining groups, WT mice and YAC128 $\mathrm{HD}$ mice, received an equivalent volume of vehicle. One cohort was behaviorally tested every 2 months, commencing at 2 months of age. Mice were tested on motor learning (rotarod training), motor function (rotarod and climbing tests), and psychiatric function (OF, EPM, and FST). Tests were conducted blindly at a set time during the day, prior to drug administration. Subsequently, these mice were scanned by MRI and sacrificed at 12.5 months of age (Figure 1A). The other cohort was scanned by MRI at 7 and 10 months of age and was used for pharmacokinetic measurement and RNA-seq analysis at 11 months of age. Sample size at each time point, as well as percentage of survival for each group, is provided in Supplemental Tables 1 and 2.

For the late treatment cohort, pridopidine was administered to animals in advanced stages of disease (8 months of age). At this age, mice present striatal atrophy and profound behavioral deficits. Animals were divided into two groups receiving either $0 \mathrm{mg} / \mathrm{kg}$ or an escalating dose of pridopidine $(10 \mathrm{mg} / \mathrm{kg}$ in week $1,20 \mathrm{mg} / \mathrm{kg}$ in week 2, and $30 \mathrm{mg} / \mathrm{kg}$ in weeks 3-8) (Figure 1B). A battery of behavioral tests was performed between 9.5 and 10 months of age. Mice were tested on motor learning (rotarod training), motor function (rotarod test), and psychiatric function (OF, EPM, and FST) and were sacrificed following completion of behavioral testing at 10 months of age (Figure 1B). Initial sample size for each group is provided in Supplemental Table 3.

Motor learning and accelerating rotarod test. The rotarod test is designed to evaluate motor coordination and balance in rodents using an accelerating rotarod apparatus (UGO Basile 47600 Rotarod, rotating rod diameter $3 \mathrm{~cm}$ ). Training was carried out at 2 months of age and consisted of 3 trials (120 seconds each) per day, spaced 1 hour apart, at a fixed speed of $18 \mathrm{rpm}$ for 3 consecutive days. The testing phase was carried out every 2 months, between 2 (baseline) and 12 months of age, and consisted of 3 trials, spaced 2 hours apart, where the rotarod accelerated from 5 to $40 \mathrm{rpm}$ over 5 minutes. Rotarod scores are the average of 3 trials. Test sessions were performed blinded.

Climbing test. The climbing test is used to assess motor function in rodents $(22,64)$. Each trial session consisted of an acclimatization phase and a test phase. In the acclimatization phase, mice were allowed to acclimatize to the testing room for at least 30 minutes before testing. In the test phase, mice were placed at the bottom end of a closed-top wire-mesh cylinder, and their behavior was monitored for 5 minutes. The time from when a mouse's 4 paws left the table top to the time when the first paw was replaced on the table top was scored as time spent climbing. The sum of climbing time for the 5 -minute trial is the total time spent climbing for each mouse. The latency at which each mouse started to climb was also measured. Test sessions and analysis were performed blinded.

Spontaneous locomotor activity test. The spontaneous locomotor activity test measures both gross and fine locomotive movements in mice. The aspects of activity measured are horizontal activity (distance traveled, ambulatory counts, ambulatory episodes, velocity), vertical activity (rearing, jumping), and stereotypy. To evaluate locomotion, mice were monitored for 30 minutes using the Med Associates spontaneous activity chambers (27.3 [L] x $27.3[\mathrm{~W}]$ x $20.3[\mathrm{H}] \mathrm{cm}$ ) with 16 beams (Med Associate Inc,). Test sessions were performed blinded.

OF test of anxiety. The OF test is commonly used to assess anxiety in rodents (65). The testing apparatus is a $50 \times 50 \mathrm{~cm}$ open, gray, acrylic box (OF) with 20 -cm high walls. Because rodents have an innate fear of open and bright spaces, they preferentially spend more time at the perimeter rather than the center of the OF. The time spent in the center versus the perimeter is taken as a measure of anxiety-like behavior. Test sessions lasted 10 minutes, and the time spent in the center versus perimeter was recorded using an automated video-based tracking system (Noldus EthoVision 9). Test sessions were performed blinded.

EPM test of anxiety. The EPM (66) is a well-established test of anxiety. The testing apparatus used has a cross-like shape with two open arms perpendicular to two closed arms of equal dimensions. The closed arms are enclosed by three $10-\mathrm{cm}$ high walls. Because rodents have an innate fear of elevated open spaces, they tend to spend less time in the open arms. Time spent in the open versus closed arms is taken as a measure of anxiety-like behavior. Generally, treatment of rodents with anxiolytic drugs that reduce anxiety increases both the amount of time spent in and the number of entries into the open arms (22). Test sessions lasted 5 minutes, and the number of entries into the open arms and time spent in the open versus closed arms were recorded using an automated video-based tracking system (Noldus EthoVision 9). Test sessions were performed blinded.

Porsolt FST of depression. The Porsolt FST was performed as described previously (27). Briefly, mice were placed in individual cylinders $(25-\mathrm{cm}$ tall $\times 19$ - $\mathrm{cm}$ wide $)$ filled with room temperature water $\left(23^{\circ} \mathrm{C}-25^{\circ} \mathrm{C}\right)$ to a depth of $15 \mathrm{~cm}$ for a period of 6 minutes. The test sessions were recorded by a video camera placed 
directly above the cylinders. The sessions were performed and examined blinded. The last 4 minutes of the test session was scored using a time-sampling technique to rate the predominant behavior over 5-second intervals. The following behaviors were measured and recorded at the end of every 5-second interval: swimming/climbing and immobility.

Brain sample preparation for histology. Mice were anesthetized with intraperitoneal injections of a ketamine $(150 \mathrm{mg} / \mathrm{kg}) / x y l a z i n e(10 \mathrm{mg} / \mathrm{kg})$ mixture. Animals were perfused at 12.5 months of age with ice-cold PBS followed by ice-cold 4\% paraformaldehyde (PFA) in PBS. Brains were removed and left in $4 \%$ PFA for 24 hours and then transferred into a $30 \%$ sucrose solution containing $0.08 \%$ sodium azide in PBS. After weighing, brains were frozen on dry ice, mounted with Tissue-TEK O.C.T. compound (Sakura), and sliced coronally into 25- $\mu \mathrm{m}$ sections on a cryostat (Microm HM 525, Thermo Fisher Scientific). The sections were collected and stored in PBS with $0.08 \%$ sodium azide at $4^{\circ} \mathrm{C}$.

Immunohistochemistry. A series of $25-\mu \mathrm{m}$ thick coronal sections spanning the striatum were stained with mouse anti-NeuN antibody (1:1,000; Millipore, MAB377) or rabbit anti-DARPP32 (1:1,000; Santa Cruz, sc11365) overnight at $4^{\circ} \mathrm{C}$ in $5 \%$ normal goat serum (NGS) and $0.2 \%$ Triton X-100 in PBS, followed by incubation with biotinylated anti-mouse or anti-rabbit antibody (1:200; Vectastain ABC HRP Kit, PK-4002 or PK-4006; Vector Laboratories) for 1.5 hours at room temperature with $1 \%$ NGS, $0.2 \%$ Triton X-100 in PBS. After 3 washes in PBS, sections were incubated in Vectastain Elite ABC reagent (Vector Labs Inc.) for 2 hours at room temperature and staining was visualized using DAB (ImmPACT DAB Peroxidase Substrate, SK-4105; Vector Laboratories). Sections were mounted on slides and coverslipped with DPX mounting media (MilliporeSigma, 44581).

Stereological measurements. The number of NeuN-positive striatal cells and striatal volume were determined by examining 6 to 9 coronal sections per mouse at $200-\mu \mathrm{m}$ intervals covering the striatum (both hemispheres). Analysis was done using the Stereo Investigator Software (MBF Bioscience) with optical fractionator (cell counts) or Cavalieri probe (volume) connected to an AxioImager M2 microscope (Carl Zeiss AG) and AxioCam MRc Digital CCD camera (Carl Zeiss AG). The following parameters were used: $40 \times 40 \mu \mathrm{m}$ counting frame size, $450 \times 450 \mu \mathrm{m}$ grid size, $10 \mu \mathrm{m}$ dissector height, and $5 \mu \mathrm{m}$ guard. For all analysis, a genotype-blinded system was used.

Quantification of DARPP32 staining by OD. Three coronal sections per mouse at $600-\mu \mathrm{m}$ intervals covering the striatum (both hemispheres) were photographed using a Ni-E microscope (Nikon Corporation) and DS-Ri2 color camera (Nikon Corporation). Mean gray value covering the striatum was measured with ImageJ software $\left(\mathrm{NIH}\right.$, version $1.50 \mathrm{e}$ ) and converted to $\mathrm{OD}$ using the following formula: $\mathrm{OD}=\log _{10}(255 /$ mean gray value) (67)

Measurement of pridopidine concentration in plasma. Blood was collected via cardiac puncture 30 minutes after dose into EDTA collection tubes (Microvette CB300 K2 EDTA, catalog 16.444.100; Sarstedt AG \& $\mathrm{Co}$ ) and kept on ice prior to centrifugation at $1,500 \mathrm{~g}$ for 15 minutes at $4^{\circ} \mathrm{C}$. The plasma was then transferred into a new tube and stored at $-80^{\circ} \mathrm{C}$ until pharmacokinetics analysis was done by Teva Pharmaceutical Industries Ltd.

Brain tissue collection for molecular analysis. Brains from 11-month-old mice were microdissected $30 \mathrm{~min}$ utes after dose, and dissected striata were kept in RNAlater solution (Ambion, AM7021) overnight at $4^{\circ} \mathrm{C}$ and then stored at $-80^{\circ} \mathrm{C}$ until use.

RNA-seq analysis. RNA-seq was performed by Q2 Solutions using standard TruSeq Stranded mRNA library preparation and HiSeq $2 \times 50$ nt paired-end sequencing. Fastq files from EA Genomics were downloaded and then aligned to GRCm38 using STAR v2.5.0a (68). The mapped reads were counted at the gene level using featureCounts v1.5.1 (69) on GeneCode vM7. Outliers were filtered out based on PCA plots. The function calcNormFactors was used to normalized the counts, and then a voom transform was applied to the normalized counts from R package limma v3.28.21 (70) in R v3.3.0. 1mFit was used to test genes for differential expression, and then empirical Bayes smoothing was applied with eBayes to the standard errors in the striatum between YAC128 HD and WT untreated samples $(10 \mathrm{mg} / \mathrm{kg}$ dose and vehicle in YAC128 HD samples; $30 \mathrm{mg} / \mathrm{kg}$ dose and vehicle in YAC128 HD samples). Gene set enrichment analysis (71) was used to test whether genes changed in the disease model were enriched for genes changed in the opposite direction in the pridopidine treatment signal and was used for pathway enrichment.

MRI, image processing, and analysis. Thirty-two animals ( $n=8$ genotype/group) were imaged on a $7 \mathrm{~T}$ MRI (Bruker, ClinScan) using a 4-channel array coil. The animals were anesthetized with 3\% isoflurane in $1: 1$ air/oxygen mixture at $11 / \mathrm{min}$ and maintained for the scanning procedure at $1 \%-2 \%$ isoflurane. Respiration rates during the scans were maintained between 90 and 110 breaths/min, and rectal temperatures were 
maintained at $37^{\circ} \mathrm{C}$ using a warm air heater. Structural images were acquired using a T2-weighted Fast Spin Echo (T2-TSE) MRI, with repetition time of 3,080 ms, echo time of $43 \mathrm{~mm}$, effective averages of 3, and $0.1 \times 0.1 \times 0.3 \mathrm{~mm}$ voxel resolution with prescan coil inhomogeneity correction. Total acquisition time was approximately 20 minutes. Structural T2-TSE images were cropped and corrected for signal inhomogeneity using MIPAV (http://mipav.cit.nih.gov/) N3 inhomogeneity correction (69). The images were then nonlinearly registered using FSL's (http://fsl.fmrib.ox.ac.uk/fsl) FNIRT (72) to an in-house created template from registered brain images of 9-month-old YAC128 and WT mice from a previous study (29).

A Jacobian determinant image of each animal can be obtained from the individual's registration process. The Jacobian determinant image reflects the volume change from the individual brain to fit the template during the registration process and can be used to run tensor-based morphometry (22). Voxel-by-voxel comparison of group Jacobian determinants was performed using spm8 (http://www.fil.ion.ucl.ac.uk/ spm/software/spm8/). The obtained $P$ value statistical map was corrected for multiple comparisons using FSL's False Discovery Rate tool (73) to obtain a statistical map with a corrected $P$ value threshold at 0.05 .

To quantify whole brain, caudate putamen $(\mathrm{CPu})$, and $\mathrm{CC}$ volumes, a whole-brain volume of interest (VOI), a CPu VOI, and CC VOI were used for quantification based on the mean Jacobian determinant inside the VOI. The mean Jacobian determinant value was then used to calculate the individual's brain volume and $\mathrm{CPu}$ volume.

Data and materials availability. RNA-seq data are available on the NCBI SRA (accession PRJNA407806, BioProject).

Statistics. Box-and-whiskers plots show median (line within box), 25th and 75th percentile (bounds of box), and minimum and maximum values (bars). Unless otherwise stated, comparisons between treatment groups were assessed using a 1-way ANOVA with Fisher's LSD post-hoc analysis. Where indicated, pair-wise comparisons between groups at individual time points were assessed with a 2-tailed Student's $t$ test or unpaired $t$ test. Statistical tests were performed with Prism v6. Differences were considered statistically significant when $P<0.05$. RNA-seq $P$ values were multiple hypotheses adjusted using the default setting in the limma R package (which is Benjamini-Hochberg). $P$ values are nominal unless otherwise listed. Information regarding sample size for the behavioral tests at each analysis point is provided in Supplemental Tables 3-8.

Study approval. Experiments were performed with the approval of the Institutional Animal Care and Use Committee at the Biomedical Sciences Institute (A*STAR) and in accordance with their approved guidelines.

\section{Author contributions}

MGM performed experiments and data analysis and interpretation and wrote the manuscript. JYT, NABMY, LJT, and XX performed experiments. YC and RK analyzed data. MG, IG, AO, and MRH contributed to the study design and revision of the manuscript. MAP conceived and designed experiments, participated in analysis and interpretation of data, and wrote the manuscript.

\section{Acknowledgments}

We thank Madeline Lim for technical assistance, Kerry McLaughlin for editorial assistance, and Lilach Steiner, Michael Burczynski, and Jennifer Dreymann for helpful discussions. This study was supported by a grant from Teva Pharmaceutical Industries Ltd. MAP is supported by the Strategic Positioning Fund for Genetic Orphan Diseases (SPF2012/005) and a Joint Council Grant (1331AFG078) from A*STAR and by the National University of Singapore.

Address correspondence to: Mahmoud A. Pouladi, Translational Laboratory in Genetic Medicine, 8A Biomedical Grove, Immunos, Level 5, Singapore 138648. Phone: 65.6407.4384; Email: pouladi@tlgm.a-star. edu.sg ormap@pouladilab.org.

1. Ross CA, Tabrizi SJ. Huntington's disease: from molecular pathogenesis to clinical treatment. Lancet Neurol. 2011;10(1):83-98

2. Ehrlich ME. Huntington's disease and the striatal medium spiny neuron: cell-autonomous and non-cell-autonomous mechanisms of disease. Neurotherapeutics. 2012;9(2):270-284.

3. Brito V, Puigdellívol M, Giralt A, del Toro D, Alberch J, Ginés S. Imbalance of p75(NTR)/TrkB protein expression in Huntington's disease: implication for neuroprotective therapies. Cell Death Dis. 2013;4:e595.

4. Zuccato C, Cattaneo E. Role of brain-derived neurotrophic factor in Huntington's disease. Prog Neurobiol. 2007;81(5-6):294-330.

5. Garcia-Miralles M, et al. Treatment with the MAO-A inhibitor clorgyline elevates monoamine neurotransmitter levels and 
improves affective phenotypes in a mouse model of Huntington disease. Exp Neurol. 2016;278:4-10.

6. Chen JY, Wang EA, Cepeda C, Levine MS. Dopamine imbalance in Huntington's disease: a mechanism for the lack of behavioral flexibility. Front Neurosci. 2013;7:114.

7. Wu J, et al. Enhanced store-operated calcium entry leads to striatal synaptic loss in a Huntington's disease mouse model. $J$ Neurosci. 2016;36(1):125-141.

8. Ryskamp D, et al. The sigma-1 receptor mediates the beneficial effects of pridopidine in a mouse model of Huntington disease. Neurobiol Dis. 2017;97(Pt A):46-59.

9. Su TP, Hayashi T, Maurice T, Buch S, Ruoho AE. The sigma-1 receptor chaperone as an inter-organelle signaling modulator. Trends Pharmacol Sci. 2010;31(12):557-566.

10. Sahlholm K, et al. Pridopidine selectively occupies sigma-1 rather than dopamine D2 receptors at behaviorally active doses. Psychopharmacology (Berl). 2015;232(18):3443-3453.

11. Hayashi T, Su TP. Sigma-1 receptor chaperones at the ER-mitochondrion interface regulate $\mathrm{Ca}(2+)$ signaling and cell survival. Cell. 2007;131(3):596-610.

12. Kourrich S, Su TP, Fujimoto M, Bonci A. The sigma-1 receptor: roles in neuronal plasticity and disease. Trends Neurosci. 2012;35(12):762-771

13. van Waarde A, et al. The cholinergic system, sigma-1 receptors and cognition. Behav Brain Res. 2011;221(2):543-554.

14. Al-Saif A, Al-Mohanna F, Bohlega S. A mutation in sigma-1 receptor causes juvenile amyotrophic lateral sclerosis. Ann Neurol. 2011;70(6):913-919

15. Luty AA, et al. Sigma nonopioid intracellular receptor 1 mutations cause frontotemporal lobar degeneration-motor neuron disease. Ann Neurol. 2010;68(5):639-649.

16. Li X, et al. A SIGMAR1 splice-site mutation causes distal hereditary motor neuropathy. Neurology. 2015;84(24):2430-2437.

17. Huang Y, et al. Genetic polymorphisms in sigma-1 receptor and apolipoprotein E interact to influence the severity of Alzheimer's disease. Curr Alzheimer Res. 2011;8(7):765-770.

18. Hyrskyluoto A, Pulli I, Törnqvist K, Ho TH, Korhonen L, Lindholm D. Sigma-1 receptor agonist PRE084 is protective against mutant huntingtin-induced cell degeneration: involvement of calpastatin and the NF-kB pathway. Cell Death Dis. $2013 ; 4$ :e646.

19. Squitieri F, Di Pardo A, Favellato M, Amico E, Maglione V, Frati L. Pridopidine, a dopamine stabilizer, improves motor performance and shows neuroprotective effects in Huntington disease R6/2 mouse model. J Cell Mol Med. 2015;19(11):2540-2548.

20. Pouladi MA, et al. NP03, a novel low-dose lithium formulation, is neuroprotective in the YAC128 mouse model of Huntington disease. Neurobiol Dis. 2012;48(3):282-289.

21. Southwell AL, et al. Anti-semaphorin 4D immunotherapy ameliorates neuropathology and some cognitive impairment in the YAC128 mouse model of Huntington disease. Neurobiol Dis. 2015;76:46-56.

22. Garcia-Miralles M, et al. Laquinimod rescues striatal, cortical and white matter pathology and results in modest behavioura improvements in the YAC128 model of Huntington disease. Sci Rep. 2016;6:31652

23. Pouladi MA, Morton AJ, Hayden MR. Choosing an animal model for the study of Huntington's disease. Nat Rev Neurosci. 2013;14(10):708-721.

24. Pouladi MA, et al. Marked differences in neurochemistry and aggregates despite similar behavioural and neuropathological features of Huntington disease in the full-length BACHD and YAC128 mice. Hum Mol Genet. 2012;21(10):2219-2232.

25. Van Raamsdonk JM, Pearson J, Slow EJ, Hossain SM, Leavitt BR, Hayden MR. Cognitive dysfunction precedes neuropathology and motor abnormalities in the YAC128 mouse model of Huntington's disease. J Neurosci. 2005;25(16):4169-4180.

26. Slow EJ, et al. Selective striatal neuronal loss in a YAC128 mouse model of Huntington disease. Hum Mol Genet. 2003;12(13):1555-1567.

27. Pouladi MA, et al. Prevention of depressive behaviour in the YAC128 mouse model of Huntington disease by mutation at residue 586 of huntingtin. Brain. 2009;132(Pt 4):919-932.

28. Carroll JB, et al. Natural history of disease in the YAC128 mouse reveals a discrete signature of pathology in Huntington disease. Neurobiol Dis. 2011;43(1):257-265.

29. Teo RT, et al. Structural and molecular myelination deficits occur prior to neuronal loss in the YAC128 and BACHD models of Huntington disease. Hum Mol Genet. 2016;25(13):2621-2632.

30. Kuhn A, et al. Mutant huntingtin's effects on striatal gene expression in mice recapitulate changes observed in human Huntington's disease brain and do not differ with mutant huntingtin length or wild-type huntingtin dosage. Hum Mol Genet. 2007;16(15):1845-1861.

31. Becanovic K, et al. Transcriptional changes in Huntington disease identified using genome-wide expression profiling and cross-platform analysis. Hum Mol Genet. 2010;19(8):1438-1452.

32. Kuleshov MV, et al. Enrichr: a comprehensive gene set enrichment analysis web server 2016 update. Nucleic Acids Res. 2016;44(W1):W90-W97.

33. Binder JX, et al. COMPARTMENTS: unification and visualization of protein subcellular localization evidence. Database (Oxford). 2014;2014:bau012.

34. Xu X, Wells AB, O'Brien DR, Nehorai A, Dougherty JD. Cell type-specific expression analysis to identify putative cellular mechanisms for neurogenetic disorders. J Neurosci. 2014;34(4):1420-1431.

35. Czeredys M, Gruszczynska-Biegala J, Schacht T, Methner A, Kuznicki J. Expression of genes encoding the calcium signalosome in cellular and transgenic models of Huntington's disease. Front Mol Neurosci. 2013;6:42.

36. van Roon-Mom WM, et al. Mutant huntingtin activates Nrf2-responsive genes and impairs dopamine synthesis in a PC12 model of Huntington's disease. BMC Mol Biol. 2008;9:84.

37. Desplats PA, et al. Glycolipid and ganglioside metabolism imbalances in Huntington's disease. Neurobiol Dis. 2007;27(3):265-277.

38. Tang B, et al. Gene expression profiling of R6/2 transgenic mice with different CAG repeat lengths reveals genes associated with disease onset and progression in Huntington's disease. Neurobiol Dis. 2011;42(3):459-467.

39. Liu X, et al. Evaluation of cerebrospinal fluid concentration and plasma free concentration as a surrogate measurement for brain free concentration. Drug Metab Dispos. 2006;34(9):1443-1447.

40. Marco S, et al. Suppressing aberrant GluN3A expression rescues synaptic and behavioral impairments in Huntington's disease 
models. Nat Med. 2013;19(8):1030-1038.

41. Rung JP, Carlsson A, Markinhuhta KR, Carlsson ML. The dopaminergic stabilizers (-)-OSU6162 and ACR16 reverse (+)-MK-801-induced social withdrawal in rats. Prog Neuropsychopharmacol Biol Psychiatry. 2005;29(5):833-839.

42. Natesan S, et al. The dopamine stabilizers (S)-(-)-(3-methanesulfonyl-phenyl)-1-propyl-piperidine [(-)-OSU6162] and 4-(3-methanesulfonylphenyl)-1-propyl-piperidine (ACR16) show high in vivo D2 receptor occupancy, antipsychotic-like efficacy, and low potential for motor side effects in the rat. J Pharmacol Exp Ther. 2006;318(2):810-818.

43. Svensson KA, Falcone JF, Johansson AM, Perry KW, Fell MA. The actions of the dopamine stabilizer ACR16, but not (-)OSU6162, in behavioral and neurochemical assays are not dependent on the presence of functional dopamine $\mathrm{D}_{2}$ receptors Papaer presented at: Society for Neuroscience (Washington, DC), Annual Meeting; 9-13 Nov 2009; San Diego, CA, USA.

44. Maurice T, Su TP. The pharmacology of sigma-1 receptors. Pharmacol Ther. 2009;124(2):195-206.

45. Geva M, et al. Pridopidine activates neuroprotective pathways impaired in Huntington Disease. Hum Mol Genet. 2016;25(18):3975-3987.

46. Bermack JE, Debonnel G. The role of sigma receptors in depression. J Pharmacol Sci. 2005;97(3):317-336.

47. Ooi J, Hayden MR, Pouladi MA. Inhibition of excessive monoamine oxidase A/B activity protects against stress-induced neuronal death in Huntington disease. Mol Neurobiol. 2015;52(3):1850-1861.

48. Ponten $\mathrm{H}$, et al. In vivo pharmacology of the dopaminergic stabilizer pridopidine. Eur J Pharmacol. 2010;644(1-3):88-95.

49. Cadet JL, Jayanthi S, McCoy MT, Beauvais G, Cai NS. Dopamine D1 receptors, regulation of gene expression in the brain, and neurodegeneration. CNS Neurol Disord Drug Targets. 2010;9(5):526-538.

50. Maurice T, Goguadze N. Sigma-1 ( $\sigma 1)$ receptor in memory and neurodegenerative diseases. Handb Exp Pharmacol. 2017;244:81-108

51. Miki Y, Tanji K, Mori F, Wakabayashi K. Sigma-1 receptor is involved in degradation of intranuclear inclusions in a cellular model of Huntington's disease. Neurobiol Dis. 2015;74:25-31.

52. Tan F, et al. The $\sigma 1$ receptor agonist 4-PPBP elicits ERK1/2 phosphorylation in primary neurons: a possible mechanism of neuroprotective action. Neuropharmacology. 2010;59(6):416-424.

53. Francardo V, Bez F, Wieloch T, Nissbrandt H, Ruscher K, Cenci MA. Pharmacological stimulation of sigma-1 receptors has neurorestorative effects in experimental parkinsonism. Brain. 2014;137(Pt 7):1998-2014.

54. Merienne K, Helmlinger D, Perkin GR, Devys D, Trottier Y. Polyglutamine expansion induces a protein-damaging stress connecting heat shock protein 70 to the JNK pathway. J Biol Chem. 2003;278(19):16957-16967.

55. Han I, You Y, Kordower JH, Brady ST, Morfini GA. Differential vulnerability of neurons in Huntington's disease: the role of cell type-specific features. J Neurochem. 2010;113(5):1073-1091.

56. Gatto RG, et al. Analysis of YFP(J16)-R6/2 reporter mice and postmortem brains reveals early pathology and increased vulnerability of callosal axons in Huntington's disease. Hum Mol Genet. 2015;24(18):5285-5298.

57. Shema R, Kulicke R, Cowley GS, Stein R, Root DE, Heiman M. Synthetic lethal screening in the mammalian central nervous system identifies Gpx6 as a modulator of Huntington's disease. Proc Natl Acad Sci USA. 2015;112(1):268-272.

58. Lee JH, et al. Reinstating aberrant mTORC1 activity in Huntington's disease mice improves disease phenotypes. Neuron. 2015;85(2):303-315

59. Taylor DM, et al. MAP kinase phosphatase 1 (MKP-1/DUSP1) is neuroprotective in Huntington's disease via additive effects of JNK and p38 inhibition. J Neurosci. 2013;33(6):2313-2325.

60. Benarroch EE. Effects of acetylcholine in the striatum. Recent insights and therapeutic implications. Neurology. 2012;79(3):274-281.

61. Pisani A, Bernardi G, Ding J, Surmeier DJ. Re-emergence of striatal cholinergic interneurons in movement disorders. Trends Neurosci. 2007;30(10):545-553.

62. Gng4: G Protein Subunit Gamma 4. GeneCards: Human Gene Database. http://www.genecards.org/cgi-bin/carddisp.pl?gene=GNG4. Accessed November 9, 2017.

63. Rosskopf D, et al. The human G protein beta4 subunit: gene structure, expression, Ggamma and effector interaction. FEBS Lett. 2003;544(1-3):27-32.

64. Brooks SP, Dunnett SB. Tests to assess motor phenotype in mice: a user's guide. Nat Rev Neurosci. 2009;10(7):519-529.

65. Crawley JN. Exploratory behavior models of anxiety in mice. Neurosci Biobehav Rev. 1985;9(1):37-44.

66. Walf AA, Frye CA. The use of the elevated plus maze as an assay of anxiety-related behavior in rodents. Nat Protoc. 2007;2(2):322-328.

67. Evonuk KS, Moseley CE, Doyle RE, Weaver CT, DeSilva TM. Determining immune system suppression versus CNS protection for pharmacological interventions in autoimmune demyelination. $J$ Vis Exp. 2016;(115): 54348.

68. Dobin A, et al. STAR: ultrafast universal RNA-seq aligner. Bioinformatics. 2013;29(1):15-21.

69. Liao Y, Smyth GK, Shi W. featureCounts: an efficient general purpose program for assigning sequence reads to genomic features. Bioinformatics. 2014;30(7):923-930.

70. Ritchie ME, et al. limma powers differential expression analyses for RNA-sequencing and microarray studies. Nucleic Acids Res. 2015;43(7):e47.

71. Subramanian A, et al. Gene set enrichment analysis: a knowledge-based approach for interpreting genome-wide expression profiles. Proc Natl Acad Sci USA. 2005;102(43):15545-15550.

72. Jenkinson M, Beckmann CF, Behrens TE, Woolrich MW, Smith SM. FSL. Neuroimage. 2012;62(2):782-790.

73. Genovese CR, Lazar NA, Nichols T. Thresholding of statistical maps in functional neuroimaging using the false discovery rate. Neuroimage. 2002;15(4):870-878. 